\title{
The organicity of science
}

\author{
Francisc Gafton* \\ Faculty of Letters, "Alexandru Ioan Cuza" University, Bd. Carol I 11, 700506 Iaşi, Romania
}

\section{Article info}

History:

Received March 31, 2015

Accepted April 20, 2015

Published July 17, 2015

Key words:

organism

natural sciences

human sciences

coevolution

culture

language

humanity

\begin{abstract}
The systemic character of entities implies their being formed of discrete elements whose conjunction generates hierarchical structures, functions, forces, and roles. While the observation and study of entities entails their segregation with respect to certain sets of criteria, their understanding follows from their thorough comprehension, in plenary connection with the environment of which they are component, product, and factor.

Having the profound role of bringing the human being in the state of knowing and understanding the Universe, science (including the methodology that invents and governs paths, and the apparatus that makes the entire endeavour operational) follows this model of specialized division. Starting from the initial common state, science develops its observations by identifying and describing the reality and its specialized components, in accordance with how they are structured and function, constantly tailoring its means of investigations to the genetic, structural, and functional peculiarities of those aspects.

The completion and evolution of science are consequent to the assimilation of this approach beyond the interdisciplinary level, and arise from the conjunction of scientific knowledge, methods, and instruments, aimed at reflecting reality in its entirety and integrality. This outcome requires a recurrent reconsideration and revision of the organism of science.
\end{abstract}

\section{Contents}

1 Introduction 2

2 Organization of reality 2

3 Communion and dynamics of structures and levels 3

4 Communication - coordination - sociality $\quad 6$

5 Organization of sciences $\quad 8$

6 The relation between reality and sciences $\quad 10$

7 Homo sapiens sapiens $\quad 13$

8 Gene-culture coevolution $\quad 20$

9 The organicity of reality and of science $\quad 29$

10 Conclusion $\quad 34$

Bibliography

*Email address: algafton@gmail.com. 


\section{"The enemy of science is not religion [...]. The true enemy is the substitution of thought, reflection, and curiosity with dogma."} (Frans de Waal, The Bonobo and the Atheist)

\section{Introduction (In principio erat principium)}

The evolutionary path of the human brain and cognition reflects the survival needs of the human being, rather than purely intellective needs. As a spatio-temporally limited being, having to process and handle a reality which he thus circumscribes and whose sources transcend him, man is able to fathom only parts of the reality of which he himself is part, a fact that does not change even after the gene-environment coevolution develops complex phenotypical paradigms.

The limits of the human mind to comprehend, the modalities in which it operates, and the needs to which it normally answers compel—and have probably always done so-the human being, in its attempt to understand reality, to engage in its division, description, definition, and classification on empirical, intuitive and rational grounds .

\section{Organization of reality (Totum est priuspartibus)}

The observation and investigation of reality reveal its hierarchical character, each level being constitutive for the next. By virtue of rather unknown tendencies, forces, and laws, subatomic particles tend to aggregate in functional structures, and consequently form atoms whose behaviour is governed by forces, laws, and physical and chemical properties. In turn, by virtue of partially known affinities, atoms exhibit the same gregarious behaviour, the resulting molecules sometimes being able to attain the ability to autoreplicate, interact, and form organisms such as the cells.

As a consequence of interactional processes, subatomic particles form the constitutive elements of the atom: protons and neutrons, which, in turn, will constitute the nucleus, and electrons. Atoms may interact and form molecules-components of the cell ${ }^{1}$.

Cells may interact structurally and functionally with other cells, becoming elements in structurally more complex organisms, forming tissues, organs, organ systems, organisms, individuals, communities. Along this progression, as the complexity increases and the hierarchical character becomes stronger, the laws and requirements of inferior levels progressively interfere, and in conjunction with the requirements of the superior levels evolve to laws accommodated to the latter, but without deviating from the fundamental principles. Therefore, on the one hand, the initial structuring of the simplest elements generates forms of organization and complex functions, while on the other hand the structures and functions of reality interact causally and hierarchically, by virtue of forces obeying fundamental principles from which laws derive ${ }^{2}$.

\footnotetext{
${ }^{1}$ The cell is a useful model for any analysis and extrapolation because it has a hierarchical structure (the nucleus-an incredibly complex entity, especially in eukaryotes, with an inconceivable structural and functional intricacy, considering that, among other things, it contains a complete set of chromosomes and controls the cellular activity by regulating gene expression-, the cytoplasm - containing numerous organelles with differentiated, complex, and conjunct functions-and the membrane-a phospholipidic biological envelope endowed with chemical and electrical selectivity) and experiences internal and external molecular interactions.

${ }^{2}$ The ability of natural mechanisms (including those of nature itself) to generate macroscopic order from microscopic disorder, at both biological and geological levels, is illustrated by A. Turing's model (Ball, 2015).
} 
Both the heart and the solar system, for instance, are unitary functional structures with laws that govern their constitution, restructuring, regeneration, operation, relation with other components, evolution, and decay. These attributes ensure internal coherency, necessary for their own survival and for the fulfilment of their roles within the functional structures of which they are part. Both are structured in the image of the whole, function by responding to some of its needs, and obey its laws, since structural integration, integrated functioning, and compliance with the general laws constitute not only the "rationale", but also the condition of their existence.

The attributes that determine survival and autoregulation within the system are means by which the latter ensures the synergy and evolutive dynamics of its parts, since the laws of each level derive from essential, universally-obeyed principles achieved in increasingly complex ways, from the element towards the whole.

From the subatomic level to the level of its whole, the physical Universe is and remains constituted of the same matter, obeying the same principled constants, the dynamics of the universal acts reflecting faithfully the traits of matter, its capabilities, and the proportions, hierarchy and necessary character of the causes.

As the formative basis of the Universe, anorganic matter is auto-identical, immuable and unevolving (this being, at least, the level of certainty at which human knowledge has so far arrived). Structures that constitute themselves into instrumental-functional ensembles are based on universal laws of matter aggregation. Organic matter is relatively stable, structurable, and adaptable to the clusters it constitutes and to its functions-the latter stemming from the relation between structures and the environment and from all the consequences thus generated-, and the transmission of information (of any kind, whether it refers to structural-functional traits, to behaviours, to the mechanisms and modalities necessary for survival, sustenance, competition, etc.) takes place within certain limits, frameworks, and proportions having the force of law and which are structurally and interactionally determined ${ }^{3}$.

\section{Communion and dynamics of structures and levels (Ergo materia in se considerata, est} una tantum omnium corporalium)

The structures of living matter are established, function, adapt, and evolve differently, depending on the complexity of the organism and the longevity of its life cycle ${ }^{4}$, both depending on the persistence and complexity of the interactions. The inferior levels of organization may be relatively stable (in situations of modest genetic complexity, or when external demands are insignificant for the given organism) or dynamic (in the case of high mutation rates or of a highly demanding environment). At superior levels of biological organization the situation is different due to the complexity of DNA (the opportunity for mutation being directly proportional to the complexity of the genetic material). Moreover, the aggregation of structures and functions generates new types of requirements of internal organization, and the possibility for new types of answers to the environmental demands 5 .

The pace of evolution of natural environments and organisms is relatively constant and slow, the energy invested in adaptation being proportional to the compulsory character of the external

\footnotetext{
${ }^{3}$ Going back to classical antiquity, the anorganic / organic division-with the observation that the former realm is governed by physical laws, while the latter by the final cause-is explained by Kant, evidently in teleological terms.

${ }^{4}$ Organisms with short life cycles, such as bacteria, are subject to intense demands and have the ability to "fragment" the action of the environment through the superposition of successive generations on the same situation in which they are involved, which boosts their group adaptability. Under the condition of normal demands, other organisms with short life cycles (aside from cases such as those of aphids, which in some periods of the year reproduce through parthenogenesis) evolve only within the limits prescribed by the interactions with the environment and by genetic mutations.

${ }^{5}$ For this relation and for the concept of 'biosemiotics', see, amongst others, Rothschild (2000).
} 
demands and of the internal pressures: since investments of energy in the direction of satisfying and sustaining complex functions through complex structures are expensive, they only occur as a result of a persistent, imperative need; in general, the prompt solution is to endow existing structures with new functions that are able to adequately respond to the demands.

The answer to interactional demands does not necessarily lead to their fulfilment or mitigation; it may generate new, nuanced demands, possibly followed by internal pressures related to the need for reequilibration and calibration of the organism and its parts-but always oriented towards and by the demands of the environment to which the organism must accommodate ${ }^{6}$. The responses may induce changes in the environment itself (Irons, 1998), resulting in increased demands, more sophisticated responses, more pressing internal needs, with possible implications on the evolutionary dynamics. The act of responding to the demands imposes the adaptation of the organism to the environment (with or without internal reequilibration), while the response to the environment results in its posing new demands. In such a case, the rule is that of becoming, based on the mechanisms of quasi-mimetic imitation and adaptation.

As the progression of (external) demands and (internal) pressures entangled in a "dialogue" unfolds, the ever increasing demands of the environment intertwine with the ever more supple and efficient adaptations of the organism (to the environment and to its own dynamics). In this process evolve the organism and the environment, their responses and demands, but also the complexity of the levels, which bring with them new demands and new pressures, all enmeshed in a game of concurrent forces.

In the first stages of childhood, the human being exhibits the tendency to produce various muscular movements as the body is training, in various ways and directions, the organs with which it has come to be equipped ${ }^{7}$. Due to the anatomo-physiological relation between lungs, larynx, buccal cavity, and nasal cavity, mammals have the ability to naturally emit sounds ${ }^{8}$-as consequence of the simple act of moving and positioning these organs, possibly in conjunction with certain physiological and/or affective-emotional states. These sounds consist of a fundamental tone with a given pitch, which may be accompanied by harmonic vibrations (overtones) of various intensities. From an evolutionary perspective, the simple ability to produce such sounds is converted (by use) to sociality, with sounds becoming symptoms and signals for other organisms. As part of certain patterns and successions, the acoustical characteristics of these sounds may acquire, on a linguistic level, the quality of distinctive traits. The anatomo-physiological aggregates in question, in addition to being components of the respiratory and/or digestive systems, acquire the role of components of the phonatory system. Upon becoming operational, sounds induce responses in the receiver and response-awareness in the emitter. The ability of the generating organs continuously co-increases in this direction, the sounds and the successions they form become increasingly accurate, both in a physical and a linguistic-functional sense,

\footnotetext{
${ }^{6}$ As evolution generates (phenotypical) possibilities of answering demands, the phenotype is what provides means of answering the challenges posed by the environment (Alexander, 1979). In such a situation, the environment may determine, stimulate, and offer-in this mediated way-instruments of response. The question, then, is whether the environment poses challenges according to its means of challenging and offering solutions, or it poses challenges in order to establish structures and functions. Since, for now, what we know and can test cannot precisely reflect reality, the answer is not based on reality but rather on the model of reality built mentally by the human being, and therefore is either deterministic or teleological.

${ }^{7}$ In fact, all movements, from the tiniest cell to the level of the entire organism, from the voluntary ones to those that will remain outside voluntary control, stem from the very life of the cells and of the superordinate structures, from their or the organism's inherent, acquired, or mixed needs. Initiated by the very existence of living matter, movements become actions through which living matter autoregulates and adapts to life, then reactions through which structures answer to internal needs and external demands, while at the same time being exercises through which structures efficiently master their functions and roles, and activities through which the structures and functions are kept in tune with the level of ongoing demands.

${ }^{8}$ The movement and vibration of atoms is a universal constant; in the terrestrial domain, air flows are able to produce "sound", a consequence that may be observed as following from the actions of countless species, even if it does not stem from the action of the same anatomical parts.
} 
and the awareness increases and diversifies its forms of manifestation ${ }^{9}$. This natural attribute is exercised by the individual in a social context, through imitation and contact, such that sounds join together in syllables, which become morphems and give rise to lexical words; the continuous exercise of language, correlated with the usages of other individuals, gives rise to grammatical rules; the speaker always notices the effects of this process, since the perception of relevant differences gives awareness and a tendency towards compatibility with the environment, i.e., to adjust to the linguistic norm of the community to which one belongs. Later on, the social (i.e., group) usage of language may be diversified and refined in the context of adaptability to various norms, and may induce a certain relation between language and thought; eventually, a refined and nuanced usage of the literary norm may be acquired, leading to the development of rhetorical (even manneristic) means of linguistic expression. ${ }^{10}$.

The simple instinctual manifestation of a range of physical possibilities at a moto-sensorial level becomes, through continuous biological feedback, automated activity and usage; following the linguistic, social, intellectual, and rsthetic awareness and feedback, the results then become components of language. Thus, a physical entity set in motion by innate tendencies of living matter becomes a functional structure and generates an activity. The structural-functional product acquires needs, evolves in the direction of both fulfilling these needs, and of its own operation and structural and functional consolidation, becomes active and acquires both the status of an individual and active entity and that of an instrument. In turn, the activity exerted through this functional structure tends to improve by continuous monitoring of its successive images and results, in relation with the possibilities of the functional structure and with the other activities and responses of the environment. The concurrent game between these two elements (the functional structure and its activity), each of which interacts with itself, with the other, and with the environment, is subject to evolution and may become an evolutionary factor.

This process can only be fully understood when examined in the details of its gradual becoming, from the complex perspective of all the levels involved (physical, biological, linguistic, social, psychical) - a path that accounts not only for the shift from the physical to the anthropic value of the entity, function and value, but also for the concordant and collaborative-evolutive connection / tendency of the elements, structures, functions, and products of the entire complex.

This "arms race" in which the dynamics stems not only from competitiveness, but also from anticipating the dynamics itself, determines individuals to develop and acquire mechanisms that are increasingly capable to process, integrate, and use information in the most efficient way, in order to devise and execute adaptive and survival strategies, anticipating and manipulating an increasingly demanding environment. As the dynamics of the environment determines and shapes the social dynamics, and the response of the latter stimulates the environment (the environment and the organism do not only coexist, but are truly equivalent, as the environment of a certain level may itself be an organism at a superior level), it follows that the environment becomes increasingly demanding and generates both competitiveness (Flinn, 1997; Alexander, 1989) and synergic action and collaboration, which brings about sociality ${ }^{11}$.

\footnotetext{
${ }^{9}$ This co-increase refers to the relation between: a) the elements of the phonatory system and its ability to generate increasingly more accurate outputs; b) the auditive system and its ability to discern increasingly finer features, which become endowed with relevance for the final process; c) the emitted sounds, the received sounds, their configuration and response values; d) the elements of the entire ensemble: the phonatory system, the auditive system, and the corresponding cortical areas.

${ }^{10}$ Similarly to how intense collisions between hydrogen atoms lead to the formation of helium, and subsequent collisions generate increasingly complex chemical elements, to the point where further interactions and effects require quantities of energy that are difficult to obtain, in the case of living matter, the structural complexity-as a response to internal needs and to external demands-is amplified in a rhythm that may become accelerated on the higher levels of complexity. On the other hand, regardless of how complex the results are, the hydrogen atoms (or, at a deeper level, the subatomic particles of which they are formed) and the principles that govern their behaviour are perpetual and self-identical.

${ }^{11}$ When two individuals detect the same pray, both initially want it for themselves. After a while, however, and especially when the pray is abundant, the two may notice that the economy of collaboration is more fruitful than the waste of competition,
} 


\section{Communication - coordination - sociality (Communication leads to Community)}

Although a typical attribute of organisms that are part of environments, communication-coordination ${ }^{12}$ is not an exclusive property (of class, order, family, genus, or species, for instance), and possible differences in nuance do not strictly and exclusively rely on the evolutionarily acquired traits of the organisms that exhibit this attribute (Choe \& Crespi, 1997).

One of the reasons for the early success ${ }^{13}$ of the human being was collaborative intercommunication. While not a human invention (under this aspect, the living cell, or, at a different level, the nerve cell offer and constitute the most typical model for all societies of organisms), it is extremely efficient since it provides - at first sight to an individual, in fact to the entire groupthe possibility to: a) achieve, on a relatively short time scale, knowledge and abilities that have been acquired along multiple generations; it would be rather unlikely for many of these elements to be acquired by a single individual through the "events" of its life alone; b) share numerous attributes that none of the members of the society possess in their entirety. In this way, the student acquires pieces of knowledge discovered before him, without going through them as effective processes and without possessing the competency or the science necessary for arriving at them independently, his only effort being that of mental understanding (imagination and reconstruction, and possibly abstractization and/or empathization, all based on experience and on exercising the acquired mental abilities) ${ }^{14}$.

In turn, microorganisms (such as prokaryotic and eukaryotic bacteria, yeast, fungi, etc.) may exhibit complex social behaviours, such as communicating and cooperating towards increasing their chances for survival (e.g., searching for and obtaining nutrients, efficient spreading, building elements necessary for life) and for reproduction. This behaviour occurs in both multicellular and unicellular bacteria (in the case of the latter being a much more significant and instructive fact), between different species of bacteria, even prokaryotic and eukaryotic, akin or not, and stems from the ability to perceive the co-presence of other microorganisms and whether they reach a critical mass, or quorum (Hagen, 2015). In this way, a phenotypical adjustment occurs through positive feedback at the individual level, as a response to the change in the concentration of "pheromones", while at a group level organisms communicate with each other and acquire the ability to produce a coordinated response ${ }^{15}$. Investigations into the molecular mechanisms at the foundation of their genetics, which allow and generate such behaviours (Wilson, 1975; Brown, 1983; Camazine et al., 2001; Hammerstein, 2003; Maynard Smith \& Harper, 2003; West et al.,

and may shift from competition, through synchronization, to collaboration. Still, the actual conditions of various kinds are variables that generate a permanent interplay between competition and collaboration, such that it is often difficult to point out which one dominates, and often one includes, substitutes, or assimilates the other, without any of them to ever truly and completely vanish.

${ }^{12}$ Communication-coordination is a fundamental attribute of matter, with an accelerative influence. Even if it stems from a certain kind of materialized energy, the simplest material element, the "atom", is communicative and communicatory through its mere existence, and from the moment it enters a relation — however simple—with a homologue, a certain kind of coordination with its homologue and with the environment arises.

${ }^{13}$ We point out that although many innovations and acquisitions have contributed to the success of the human species, since they are not restricted or exclusive to the human being, their real success does not stem from their appearance and functioning, but from their conservation and development within an efficient constellation.

${ }^{14}$ At a technological level, the pilot of a space shuttle benefits from all the science and technology of those who designed and built the ship; at a more spectacular but superficial level, those with an earplug will benefit from the (intelectual, socialbehavioural, psychological, etc.) competencies of those connected to the system.

${ }^{15} \mathrm{~A}$ study documented through research of unicellular microorganisms such as bacteria and fungi, and concerning their means of communication, is presented by Wuster \& Babu (2007). Applied analyses of the means by which cell colonies evolve and interact with the environment are presented by: Ben-Jacob et al. (1998); Crespi (2001); Bassler \& Losick (2006); Keller \& Surette (2006); Dubern \& Diggle (2008); Nadell et al. (2013); Gloag et al. (2015). 
2006; West et al., 2007b; Joyce et al., 2013), reveal implications at a socio(micro)biological level (Parsek \& Greenberg, 2005), able to advance and bring new perspectives to the theory of evolution. In this framework it is relevant that, on the background of the existence of an ability for communication and cooperation in microorganisms, just like in other living beings, one can identify the existence of parasites, i.e. of individuals that "cheat" the game by solely benefiting from the cooperation without investing in it. Since (for efficiency reasons) certain group actions do not commence until the number of individuals reaches a critical mass, a quorum, which is detected based on chemical communication, there are individuals who do not contribute (proportionally or at all) to the communal effort, while reaping the benefits, or, more sophisticatedly, transmit quorum signals without a quorum being actually achieved (Czárán \& Hoekstra, 2009). A corresponding type of intercommunication (very approximately, though still comparable) is also present at the anorganic-and actually quantum-level, in what is known as entangle$m e n t^{16}$.

Within the environment, the relation between the individual and the group is centred around survival and adaptation conducive to survival. These simultaneously represent stakes, causes, means, and effects, the perspective of this duality being pivotal to the understanding of the elements and of their structural organicity, of the functioning and creation of the mechanisms and instruments of an efficient, structuralphysiological and adaptive evolution ${ }^{17}$.

The existence and survival of an individual within an environment depend on its ability to adapt, to modify the demands and constraints of the environment, and on the fact that the latter may stimulate and determine the appearance of new means of adaptation to its variety of challenges, some of these means_-such as sociality_bringing along consistent modifications, in regard to both the capacity for development and the need for new customs, accommodated to the interactional and evolutionary state of the individual and of the community. As a result of such needs, individual and communal customs emerge at the articulation between the functional structure of the living organism and the demands of the environment, such that the adaptive tendencies and capabilities, together with the sociality of living beings ${ }^{18}$, constitute premises for their evolution.

In the case of microorganisms (such as those discussed above), the gene that triggers, stimulates, and maintains communication and the cooperative behaviour is synergic (that is, it stimulates behaviours that are advantageous for all the individuals that spend energy in the benefit of the group, but does not stimulate altruistic behaviours ${ }^{19}$ through which some individuals expend

\footnotetext{
${ }^{16}$ The term (rendering Germ. Verschränkung), created by E. Schrödinger in 1935, refers to the tendency and ability of two or more physically separated particles to have a conjunct behaviour, a fact with deep implications on the nature of time, information, and energy in general. Apart from the famous thought experiment of the cat (in fact, identical to the illustration given by Hume, $1987, \$ 70$, where the Scottish philosopher discusses about necessity by using the image of a purse full of gold left for an hour on the pavement at Charing Cross), the subsequent researchers theorized and experimentally proved the initial intuition, with such experiments being more advanced than the scientific explanations regarding the phenomenon itself: Bell (1987), Kohlstedt \& Kaiser (2003), Matthew (2012).

${ }^{17}$ The set of traits that, both at a structural and a behavioural level, refers to fulfilling the primary needs (food, security, reproduction) has suffered adaptations and evolutions reflected at a behavioural level.

${ }^{18}$ Regarding the human being, one may argue that it is eminently social; however, a better insight into the nature of reality reveals that sociality is a defining characteristic of all living matter.

${ }^{19}$ Collaboration may result in altruism as a side effect-as a mechanism of preventing extreme differentiation. Altruism, however, does not exist in a pure state, and it does bring a reward even in situations of an apparently inefficient investment of energy. When promoted to the point of being implied, embedded mentally and behaviourally, it loses its nature and role until it generates the isolation of what is normal, its de-selection and anti-selection, the result affecting not only individuals (the apparent "beneficiary" who receives an undeserved amount of energy, and the altruist, rewarded mostly socially and psychologically), but also the community, which thus modelled arrives at inherent disequilibria owing to the breaking of the natural laws - the engine of evolution and existence, which the human being cannot truly manipulate.
} 
energy, while others benefit from the results) and generates efficient behaviours in akin organisms ${ }^{20}$. Social evolutionism in microorganisms goes from rewarding cooperation and the degree in which organisms participate in it, to punishing opposite situations. In general, such situations show quite clearly that the interplay and the battle between individual and group may be profitable for both sides, as long as the principle of natural selection functions normally. While the supremacy of the group is the rule, its absolute domination on the individual is harmful to the group's abilities to develop supple and efficient mechanism for adaptation to the dynamics of the environment. On the other hand, the undermining of selection, the anti-selection, and the domination of the individual are disastrous not only for the group as an entity, but ultimately for its elements as well. Similarly, the modifications-in any direction-induced in the environment are quite naturally outside the control of its inhabitants, the long-term effect being potentially catastrophic $^{21}$.

\section{Organization of sciences (Grammatica una et eadem est secundum substantiam in omnibus lin- guis, licet accidentaliter varietur)}

The mental habit of sectioning reality according to certain formal, material, or functional criteria, or according to certain social-human perspectives and needs, constitutes a means of tackling reality and of solving problems developed as a consequence of evolutionary pressures. In turn, the study of reality offers the best results when operating from multiple perspectives, generated by complex modalities and instruments, created in the image of reality and not necessarily as it is perceived and conceived by the human intuition and experience ${ }^{22}$. On the other hand, the illusion of dividing reality into pieces ought to avoid forgetting that sections and classes are created by the human mind, and definitions are constructed as if reality has already been fully understood; in fact, they are "working" theories, generated by trial and error and not by absolute knowledge. Useful for the understanding of the structures and purpose of the parts in relation with the whole whom they serve, the effort of making these divisions ought to be followed by the reunification of sequences within the functioning whole. In fact, the very object of research requires a mixture of approaches: fragmented and integral, synchronic and diachronic, special and general, adapted to the possibilities offered and imposed necessarily by reality, the adaptation to the object being the intermediate step between the general view and the detailed analysis, along the path of the unifying synthesis.

\subsection{Interdisciplinarity}

When issues arise that are claimed by multiple sciences, or that cannot be clarified by the instruments of a single science, it becomes apparent that such interferences reflect the complex nature of reality-with the difficulties deriving not so much from the inadequacy of the perspectives and of the instruments to this nature, but from the inextricable character of reality, and from the lack of a parallel existence of a science endowed with the conceptual and methodological complexity of reality itself.

Emerged as a necessity, interdisciplinarity exceeds the analyses and syntheses of the sciences centred on their own object of study, on their own methods and instruments, and interconnects elements and procedures pertaining to different sciences, especially the ones at the boundary of different domains

\footnotetext{
${ }^{20}$ For the relation between genetic kinship and cooperation, and for the promotion of gene cooperation, see Ackermann $\&$ Chao (2004), Foster et al. (2007).

${ }^{21}$ For the situation of a complex organism with a state of normality different from that of a colony of unicellular organisms, see Michod \& Roze (2001). For the change from unicellular to multicellular organisms, and the associated shift in the emphasis of natural selection, from the individual to the group and to the cooperation of the cells, with all the ensuing consequences, see Rainey \& Rainey (2003); for the social life of microorganisms, see West et al. (2007b). For inter-species cooperation, see Thompson (1999).

${ }^{22}$ We understand experience in the sense of the intellective process of knowing reality, from the perspective of Hume (1987).
} 
(Interdisciplinaritatea; Thompson Klein, 1990, 1996). The palliative effects are inherently overcome by the same tendency to partition reality, since the approach is no longer concerned with the internal unity of the object on scrutiny - though it does respect the unity of the various disciplines by not operating on their real conjunction-and naturally tends to only inspect the interconnected areas, to relate sections of the various sciences, devising the so-called "boundary disciplines". In this way, sciences acquire friable regions, the perspectives interfere in a somewhat unrealistic way, and such sciences become paths on which one may rather observe the areas of juxtaposition or of relation, than the vision of the parts and of the whole. The existence of crossing areas further separates the central zones, creating highly contrasting distinctions that can yield the illusion of a clear definition of concepts - the senses and the mind perceiving and grasping contrasts much easier, which is also the result of an evolutionary acquisition-, but with an increasing neglect of the true constitutive-functional nature of reality. On the other hand, the application to the perimeter thus isolated of perspectives, methods, and instruments belonging to both or all disciplines involved is a welcome collaborative exercise between sciences.

Interdisciplinarity in natural sciences usually operates rather efficiently, which is an indicator of the high level of interconnection and depth reached by the knowledge and methodology of these communicating vessels. The refinements of human (i.e., social and cognitive) sciences is rather an indicator of the speculative and confused level into which they have withdrawn, as a consequence of the analyses - with their own methods and instruments-of a material that does not exclusively belong to them, and, in particular, whose nature and functional structure they do not fully apprehend from the mandatory perspective of the sciences that initially discovered and brought forth that material ${ }^{23}$.

\subsection{As if}

The shortcomings of the receptors and of the analysers, the significant possibilities of flawed interpretation and reasoning, the continuous reciprocal accommodation of the elements in this conjunction constitute weaknesses that call to be corrected through rigorous means, based on empirical certainties and verified by mathematical and logical arguments. The sinuous path that science must often travel cannot hinder it from constituting (itself into) an accurate and faithful reflection of reality. In addition to the numerous serendipitous discoveries (of realities, phenomena, and ideas), and to the correct intuitions and inferences-some abandoned or cast into the shadows-, the last 2500 years of human sciences often produced extremely coherent ideaistic constructions.

The way in which reality appears to be constituted and to function reveals that the perspectives of the natural sciences and those of the human sciences are sometimes intertwined in ways that are not naturally prone to segregations. The consubstantiality and synergism of reality are thus revealed, together with the need for, on the one hand, the sciences concerned with its study to reflect this at the level of their conclusions, and on the other hand, the structures, actions, methodologies, and instrumentary to be guided by this model ${ }^{24}$. The adoption of this direction could derive from the understanding and

\footnotetext{
${ }^{23}$ It is noteworthy that, quite often, biologists advise anthropologists and psychologists to start off from the solid ground of the natural sciences, instead of ignoring the actual measurable data and therefore conceiving experiments and theories that illustrate preconceptions (Morris, 1999; Boesch, 2012; Deacon, 2012). This is one of the situations in which it is evident that the methods and conceptual dominants of particular sciences influence thought in every aspect.

${ }^{24}$ This approach of understanding things arises even in the arts (which are not the concern of our discussion), where a recurrent opinion is that they should reflect reality and/or express it with their own means. Since this discussion is exclusively focused on the sciences, we are not concerned with the authors that programmatically apply Darwinism in judgements outside the realm of science, a situation that has been occurring since the end of the 20 th century (Nesse, 1995; Carroll et al., 2015).

The endless capability of the theory of evolution to stand as solution in all fields of science, the amplitude and suppleness with which it contains them, its universality—stemming precisely from its indication of the principles that generated the dynamics and variety of life-have been noticed early on, a fact that - apart from the scientific criticisms-was reflected through the improvements brought by those who had understood Darwinism (Baldwin, 1909). But there is a trap. Since, in essence, all
} 
acceptance of the need for close collaboration between sciences, for their reconfiguration in the image of the reality which they aim to comprehend (Prigogine \& Stengers, 1984; Wilson, 1998; Jung \& Pauli, 2012; Popper, 2002, 2012).

The result of not carrying out the task of comprehending, tackling, and understanding reality in its own ways - without the reification of science-is the establishment by man, aside from the natural edifice of reality, of an ideal edifice that becomes a beacon for all human thought and action ${ }^{25}$, with the double effect that man intervenes in evolution without comprehending it-and without being a superordinate factor of its fundamental principles-and that he interferes with reality and deforms it $^{26}$ to the point where it reacts.

Between the unitary character of reality, its infinity of nuances, its frequent lack of formal differentiation-contrasts and asperities being located within its divisions rather than between them-, on the one hand, and the partial way in which the human receptors and mind can perceive and process reality ${ }^{27}$, together with the defective and imperfect character of the scientific methods and instruments, on the other, there is a rift which can, perhaps, be overcome with two resolute steps: a cognitive-mentalitary one, and a methodological one.

\section{The relation between reality and sciences (Veritas est adaquatio rei et intellectus)}

Although at the level of a given science, certain pieces of information and knowledge, conclusions, methods, and instruments must evidently precede others, and must be handled in certain ways, characterizedamongst other things-by successivity - the understanding of the system following observation, experiment, and theoretical assimilation, but also stemming from the understanding of its evolution-, in the case of science as a whole this fact is no longer as evident.

The causality and hierarchy that dominates the structures, functions, genetics, and evolutionary dynamics of reality ought to be reflected in the realm of science, which preoccupies itself with reality in a differentiated and specialized manner, as it is circumscribed by the human mind and tailored to the contemporary human understanding. Considering how (natural) reality is constituted, perhaps the best and most correct way to understand the elementary and the complex processes of its constitution and functioning is to observe the structure, functions, and abilities of its elements and principles, and to process them rationally. Emerging from the need converted to instinctive curiosity (easily elevated to a reflective, ideal, non-physiological activity), the disciplines of human scientific knowledge have to follow the organization of reality.

products of reality have the same underlying principles of structure and function, as well as the same underlying elementsthe structural-functional complexity and the transformation of complex structures into elements not invalidating the initial essence of the principle and the element, and the various levels of complexity remaining pervaded by (or acquiring) the nature of the essences-, it is easy to confuse the prime principle and element with its derivatives. Hence, while observing how the prime element becomes by evolutionary means, and how the principle successively animates increasing levels of complexity, it is possible to forget that this occurs by virtue of the overarching action of the principle-the entire variety of reality reflecting the fertile potential of the starting point, its force of erecting increasingly complex structures, endowed with functional capabilities based on those structures and obeying the laws that derive from them-and to consider that at successive levels there are successive principles, or that the process of becoming brings with it such profound transformations (qualitative leaps) that it could possibly generate new starting points.

${ }^{25}$ For the principle of fictionalism see Vaihinger (2001).

${ }^{26}$ This is an area that periodically swells and recedes - that last such period starting in the '60s-'80s-, together with an entire ideology centred on 'anti-selection', which can be somewhat spectacularly illustrated by the ideas of the Neo-Darwinist Dawkins (2001; 2009), who considers himself a militant for an anti-Darwinian society (in an ideological and behavioural sense). This fact is tantamount to the attempt to take over nature by one of its elements, to the rejection of natural laws and the attempt to institute laws conceived by the neurological processes of the tiny human being; however, by eliminating the filters of natural selection that have actually led to the emergence of the human civilization, this cannot further evolve, but only regress.

${ }^{27}$ The human mind normally perceives and understands far easier the correlation between the formal differentiation and that of content, and has an enormous propensity for definitions, classifications, and interpretations that make nearly absolute distinctions (even if they are ultimately just mental constructs). 
The bedrock of all sciences and of the entire human understanding is physics (physis), as it explains the fundamental means by which the constitutive particles of reality are structured, interact, form hierarchies, and become to the level of the Universe, fulfilling the fundamental forces by obeying them. Here are the elements and principles that govern existence and lack thereof. In turn, chemistry explains how these particles interact, form hierarchies, and become from an atomic and molecular perspective, while biology observes how living entities interact, form hierarchies, and, in contact with the environment, acquire the defining capability for organic becoming. Established on the grounds laid by physics and chemistry, biology connects the foundation of science (the natural sciences) with its derivatives [the human sciences (social, of mind, of language, etc.)] that directly or indirectly arise from it, endowing them with guiding concepts and principles founded on the most certain reality (Worms, 1895). This is the model that optimally reflects the organic character of reality and of science, as well as the likewise organic relation between the former and the latter.

In light of this, the scientific flux should be constituted and should navigate in the order of reality, and the means of the human sciences of approaching it, as well as their functioning, should unfold according to those of the natural sciences, while their judgements should not be flawed as compared to the correctly grounded conceptions of the basic fields (Degler, 2011; Barkow et al., 1992); that is, the fulfilment of the needs of the secondary sciences should not damage neither the principles and valid conclusions of the primary ones, nor the integrity of the entire scientific system.

During their evolution, some of the sciences have stagnated, regressed, or suffered for not understanding the necessity to reflect reality and assume a role proportional to their perspective, such that the mental construction of reality has reflected the perspective of that domain, as opposed to the organism of science reflecting that of reality. Although unrealistic, the claim of philosophy to the title of "queen of sciences" was understandable, as-one way or another-all sciences emerged from it (philosophy encompassing at one point physics and gnoseology with all their branches). Tearing apart sections of the common trunk, the sciences have inevitably arrived at the situation of handling aspects outside of their nature (as they had defined it), and which they could not manage. The development and expansion of knowledge have led to the expansion of the body of science and brought about specialization, which imposed the strategic need to operate divisions that would allow accurate and efficient approaches. The whole, however, was far from being understood, and was merely intuited. Even though there may have been a certain organic vision, it could not be efficient because organic knowledge and understanding were lacking; although the articulated vision was starting to take shape, the level of knowledge was hindering it from producing effects. The division, therefore, could not have been adequate, and the sciences participating to this schism came into the possession of foreign elements. On the other hand, regardless of the path that would have been taken, the result could not have been better since the object of division was a complex organic reality-an economical and efficient organism, inextricably structured, with multiple overlapping functions, with collaborative and hierarchically integrated elements-, an accurate partitioning being an impossibility. The separation may have been done correctly only by possessing knowledge that the separation itself would have provided, a vicious circle that could only have been broken by separation. In turn, the drawbacks of various means and instruments remained a constant weakness, leaving imprints both on the division and on the subsequent activities. In spite of the obvious discrepancy between the separation of sciences and reality, this path started to become the realistic solution to the needs brought by special research in various subfields and of components of various widths and depths ${ }^{28}$.

\footnotetext{
${ }^{28}$ Agnosticism and scepticism cannot get past the reaction of rejection, as they are forms of renunciation and inaction, a fact that profoundly contradicts any vital principle. They may, at best, generate a compassionate respect, akin to that felt for an anchorite.
} 
The coherence and benefits generated by philosophy stem from the essence of its object and from its central concerns: the cognitive processes, methods and instruments, the structure, functions and interactions of the elements of reality; in fact, the sciences have been generated by its need to accurately understand the complexity of the world. The shortcomings arose, of course, from the unnatural imposition of a guiding role, its (not just epistemological) principles sometimes being prioritized over any results or realistic needs of the other sciences.

The rule of philosophy marked the sciences, the domination of theology marked the scientific research. Being an ideology, theology positioned itself ahead of knowledge. In a sense, whether Omar pronounced or not the words attributed to him by Bar-Hebræus Abu al-Faraj ("If those books are in agreement with the Quran, we have no need of them; and if these are opposed to the Quran, destroy them"), the action of religion has been - though not always and not in each and every cultural-human space-exterminatory with any form or means of existence (concrete, behavioural, mentalitary, even natural) different from itself. What has driven the mistical-religious mentality was precisely the annihilation of alterity, either by elimination or by total conversion. Being areas of freedom par excellence, neither reality nor science were able to develop under the domination of such a mentality, since "There is no method of reasoning more common, and yet none more blameable, than, in philosophical disputes, to endeavour the refutation of any hypothesis, by a pretence of its dangerous consequences to religion and morality" (Hume, $1987, \$ 75)$. Since, regardless of its name, appearance, or any other sensible attribute, an ideology naturally tends towards rejecting any form of genuine freedom, the surrounding entities being only slaves that exist exclusively to serve it, whose lives are to be strictly and entirely controlled according to its needs, such a condition disturbs, deforms, and blocks the relation between thought and reality, being destructive for thought and even for reality ${ }^{29}$.

Just like the reality which they observe, sciences evolve in breadth and depth. At the expense of longer communication paths between them and of impeded information exchange and processing, they become increasingly complex and nuanced, which amplifies their bases of development, and sometimes forces them towards both segregation into subdomains and fusion of their parts, which, among others things, leads to the emergence of interdisciplinary sciences. All these forms of evolution impose periodic adjustments, aimed at inhibiting the hypertrophy of their body, the suspension of intercommunication, and their mutual isolation and isolation from reality.

Apart from their own research concerning specific situations, the efficient effort should be aimed towards the connection and collaboration between sciences, in the sense of the exchange of information at the level of content, principles, methods, and instruments - with necessary adjustments to the research of the specific situations at hand. This fact would be capable of improving the entire conceptualmethodological construction of the human sciences ${ }^{30}$. Just as important, however, is for partial results not to be withheld within the various fields, and for general conclusions to be emitted jointly-to the extent that is possible-after the correlation offered by research done by different sciences ${ }^{31}$.

As always when human will is exerted upon nature, actions with dire consequences may ensue. As

\footnotetext{
${ }^{29}$ The presence and involvement of ideological stakes cannot be rationally explained by anything but evolutionary calculations on periods that are increasingly shorter in relation to the evolutionary dynamics. Nonetheless, such stakes are harmful and aberrant since they prompt and enact actions as if human beings were all-knowing and capable of manipulating reality in all respects.

${ }^{30}$ Quite often, even the act of borrowing and using methods and instruments-while constantly monitoring the relation between their means of manifestation in other sciences and the morpho-physiological particularities of the science by which they are imported-is looked upon with hesitation, or even downright discouraged. One should, of course, make a distinction between: a) the refuse to operate in a field with improper or deforming methods and instruments; b) the rejection of a preoccupation for understanding knowledge specific to other fields, aimed at maintaining an illusory autonomy; c) the acceptance of methods and instruments belonging to certain fields, but which prove useful in other fields as well (Degler, 2011).

${ }^{31}$ Syntheses always emerge, though not everyone participates in them. Adopting conclusions by general consensus would
} 
always when human conscience guided by rational-moral principles intervenes, the situation may improve. In general, human (social and cognitive) sciences tend to disregard the foundation of reality procured by the natural sciences, while the latter-calculating and examining the verifiable and reproducible observations and experiments - tend to let themselves be guided only by the inertia of their own progress.

Regardless of how thought-provoking or fruitful they may seem, the products of human sciences cannot disregard the material body and the natural laws. Regardless of how real and profitable the basis constituted by the natural sciences is, since scientific research is ultimately a human activity and product of the human brain, this form of liberty ought to bow to the understanding and assumption of necessity, science not being a means to follow all theoretical possibilities that arise. Both domains have to regard the consequences (in a natural, not ideological sense) for humanity of some of their actions. It is true that such a selective process is difficult and entails great responsibility, and the danger of repressing beneficial paths is real-as proven by multiple centuries and pivotal historical moments. Nevertheless, this is a place where the usefulness of one of the products of science-the ability to develop human conscience-becomes apparent ${ }^{32}$, this product of matter being an excellent model of symbiosis. As science is an activity of the human mind through which one attempts to understand reality in order to act within and upon it, both natural and human sciences may participate and be involved together in the task of reining in negative tendencies and of balancing the entire process, the existence or activity in itself and for oneself not being a beneficial goal, regardless of its practicality.

One of these groups should not think while ignoring matter, the others should not think against the order of the natural laws they themselves discover, and both the ideas and the actions should be overseen. Ultimately, natural sciences teach that survival and reproduction are the central stakes, consistent with the observation that when humans and ideas enter into irreconcilable conflicts without the possibility of cohabitation, the path is not to give up the humans, but the ideas (Wald, 1970, 1983). Recognizing themselves in their most noble product, the human conscience, humans may ground their lives as moral beings upon the principles of reason, herein lying the binding material and the beacon for any modality of human existence.

\section{Homo sapiens sapiens (Prima sum: primatum nil a me alienum puto)}

Although animals have always been studied ${ }^{33}$, and the anecdotal evidence is abundant, humanity, regarding itself as profoundly different from the other animals, has not yet found scientific means to fathom their language and neuronal processes ${ }^{34}$, their ethology, sociality, and culture, except after the middle of the $20^{\text {th }}$ century, and coordinated, relevant, and valid applied studies - that connect the intellectual and empirical knowledge, without omitting the inductive method-have only appeared in the last few decades.

People have studied, amongst others: insects such as bees (Buchmann \& Reppelier, 2006; Winston, 2014) and ants (Hölldobler \& Wilson, 1990; Rico-Gray \& Oliveira, 2007; Keller \& Gordon, 2009; Hölldobler \& Wilson, 2009; Gordon, 2010), mollusks - especially gastropods and

bring progress to the science of humankind, at a rate warranted by the real value of the scientific community, but this may be hindered by a lack of debates in a common space (a shortcoming that the contemporaneous scientific world of the US, Western Europe, and Southeastern Asia tends to eliminate-at the moment in an efficient way). As the "council room" is half-empty, those who participate in the syntheses draw conclusions from the perspective of their own space, while their knowledge in various fields that should have participated to the synthesis is, at best, mediocre. At the level of the entire scientific research, these types of situations generate disagreements with reality, and consequently the inefficient or deficient functioning of the sciences.

${ }^{32}$ Human perfectibility represents the possibility of its becoming, after accepting the limits and errors as intrinsic attributes, followed by a search for means of improvement, especially in the context of accepting that the human being belongs to an evolutionary sequence, individuals and generations having responsibilities towards future generations.

${ }^{33}$ From the rich literature since the emergence of Darwinism, we refer our reader to Romanes $(1884 ; 1900)$ and Thorndike (1911). For the earlier situation, see Osborn (2014).

${ }^{34}$ Non-neuronal organisms may still take complex decisions in regard to possible alternatives related to food, environment, or reproduction (Reid et al., 2015). 
cephalopods (Hochner et al., 2006; Wollsen et al., 2009; Alves et al., 2013), amphibians, fish ${ }^{35}$, reptiles such as lizards and snakes, birds such as woodpeckers (Tebbich et al., 2001), jays (Clayton, 2007; Emery \& Clayton, 2008; Watanabe et al., 2014), crows (Hunt, 1996; Hunt \& Gray, 2003a; Hunt \& Gray, 2003b; Taylor et al., 2012) and parrots (Auersperg et al., 2012; 2014), mammals such as elephants (Moss, 1988), cetaceans (Kopps et al., 2014; Krützen et al., 2014), caniforms, feliforms, rodents, and, evidently, apes (chimpanzees and bonobos, gorillas, orangutans, and gibbons) and monkeys (baboons, macaques) (Goodall, 1964; 2010; deVore, 1965; Nishida, 1968; Premack, 1971; Fouts, 1973; Terrace, 1979; Patterson \& Linden, 1981; SavageRumbaugh et al., 1985; Savage-Rumbaugh et al., 1986; Wallman, 1992; McGrew, 1992; 2004; Parker \& Gibson, 1990; Savage-Rumbaugh \& Fields, 2000; van Schaik \& Knott, 2001; LadyginaKohts \& de Waal, 2002; de Waal, 2006; van Schaik et al., 2003; Hobaiter \& Byrne, 2011; Boesch, 2012; Schrier et al., 2013, etc.). Because these studies-numerous, well-documented and grounded in well-designed and carefully executed observations and experiments-are relatively recent, they are to be found mostly in research papers, the syntheses being still rare and more cautious in making firm statements than the original research ${ }^{36}$.

Without the mysteries of language, thought, culture, civilisation, or human psychology having been already unveiled $^{37}$, this is precisely the basis on which the human being defined and established its most defining and exclusive attributes: the ability to conceive, build, and use tools (Goodall, 1964; Lefebvre et al., 2002; Kenward et al., 2005; Bania et al., 2008; Furlong et al., 2008; Herrmann et al., 2008; Lefebvre, 2013; Pruetz \& Bertolani, 2007; Whiten et al., 2005) ${ }^{38}$, the capacity for memory, imagination, and cognition (Russon et al., 1996; Whiten et al., 2004; Hare et al., 2000; Hare et al., 2006) ${ }^{39}$, the ability to make associations ${ }^{40}$ and to be aware ${ }^{41}$, to learn ${ }^{42}$, to plan, that is, to forecast and construct the future (Bugnyar

\footnotetext{
${ }^{35}$ For learning abilities, social organisation, and personality in fish, see Crown et al. (2011). For the sharks' ability to make associations and behave accordingly, to learn, memorize, use tools, and for the ability of young sharks to use socially-acquired information about new elements in the environment, see Guttridge et al. (2009; 2013), Guttridge \& Brown (2014), Schluessel (2015).

${ }^{36}$ The syntheses seldomly belong to field researchers, though when that happens they are, in general, more assertive. As a rule, theoretical researchers are more reticent to new perspectives, and to re-evaluations with major implications.

${ }^{37}$ There is truth in the statement that, in general, we know less than we affirm, we define without having sufficient scientific data, and we judge in an anthropocentric way even though humans are too little understood by humans (Boesch, 2012).

${ }^{38}$ For the neurological basis of tool use and the stages of this process (the development of the brain area that controls grabbing and holding objects, of an area specific for instruments, and the subsequent understanding of the relation between a tool and the goal of its use), see Orban \& Caruana (2014).

The use of tools is commonplace in at least three phyla and seven classes of animals. For the inheritance and individual or social acquisition (especially via imitation) of tools, see e.g. Auersperg et al. (2014); for their spontaneous creation, see Auersperg et al. (2012). A history of the attempts to define tool use in animals-with the observation of the particularities of their usage by different classes and families of animals - and of the categories of tools and the correlated types of behaviours is given by Bentley-Condit \& Smith (2010).

${ }^{39}$ For imagination and thought (with the ensuing consequences: consolidation of experience, projection of the future, translation of solutions) developed by various cerebral structures that appear historically and procedurally in order to answer the needs of beings that are part of a social life, see Walker (1983), Emery \& Clayton (2004), Taylor \& Gray (2014).

${ }^{40}$ Natural selection favours associative learning (Leadbeater, 2015).

${ }^{41}$ For behaviours of collecting — in a discriminate manner, according to the sources (N.B.) - information needed in order to solve problems, a fact that points towards the presence of metacognition, see Watanabe et al. (2014); see also Nelson (1992), Dall et al. (2005), Beran et al. (2010).

${ }^{42}$ Being an ability developed as a phenotypical trait, learning stems from natural selection, its processes being coupled to genetic and biological adaptation, its mechanisms being products of natural selection, which it reflects. Being a consequence of interactions with other individuals, learning and transmission are not exclusively human attributes, and are in fact remarkably common in all social beings (Heyes, 1994; Csibra \& Gergely, 2009; Cheke et al., 2011, Whiten et al., 2011). Starting from the physiological reactions to the environment, going through the trial and error process, reaching observation and imitation, individuals acquire increasingly efficient means of both functional and behavioural adaptation to increasingly demanding environments (Rendell et al., 2010). Social learning, having various degrees of complexity, specificity, and function (Lumsden \& Wilson, 2005), allows not only the observation of reactions and behaviours in others, the creation of a mental image, and
} 
et al., 2007) ${ }^{43}$, to empathize, to establish a culture (Bonner, 1980; McGrew, 1992; Rendell \& Whitehead, 2001; van Schaik et al., 2003; McGrew, 2004; Sapolsky, 2006; Matsuzawa, 2008; Laland \& Galef, 2009), to develop language (Hockett, 1960; Lenneberg, 1971; Gardner et al., 1989; Savage-Rumbaugh \& Fields, 2000; Théoret \& Pascual-Leone, 2002) and creativity ${ }^{44}$.

After over a century from the formulation of the theory of evolution-the first great step that rescued humanity out of a millenary illusion by describing the unity of living matter and the modalities in which it evolves-, it is still unclear for many people that all the attributes in the above sequence can be observed in numerous species of animals, from the smallest to the largest ${ }^{45}$. The fact that some of these attributes are expressed differently than how they are defined by humans-who themselves established criteria according to their own species-is only sometimes concordant with reality, and even in such cases the differences do not modify the rank of the respective attribute ("If man had not been his own classifier, he would never have thought of founding a separate order for his own reception”, Darwin, 1875; see also Penn et al., 2008; Mesoudi, 2011) ${ }^{46}$.

the reproduction of behaviour, but also learning from the experience of others, the construction of mental scenarios able to modify behaviour, which requires space to store all the information; at the same time, it enables faster adaptations than genetics, and new cultural forms of evolution (Whiten et al., 2007b). The differences between various species in learning and the ensuing behaviours and results are phenotypical adaptations generated by natural selection, the transmission of facts acquired by learning depending on their usefulness at an evolutionary level (Flinn, 1997). Unlike other animals, humans have an extremely long period of learning and specialization (a fact that leads to specialization and depth of activities, to the development of their variety, and to the differentiation of mental requirements). They are capable of focusing on the process, not just on the goal, and to build upon something pre-existent: new upon old, unknown upon known.

Evidently, the difficulty of distinguishing with accurate instruments and based on sound principles, beyond any interpretation, between social and asocial learning, and between the various types of social learning, remains very much a reality, but the (in)existence of these aspects cannot be presumed for one or other of the species.

${ }^{43}$ For the occurrence, at some animals, of episodes that reveal (through behaviours linked to hiding food) the ability to adjust behaviour based on past events and on possible future needs suggested by past events, and for the planning and prediction of future events-an attribute that is neither innate, nor exclusively human-experimentally tested in some species of jays, through the observation of the ability to anticipate by making food deposits in (spatiotemporal) conditions of famine, see Clayton et al. (2003). Even more interesting is the fact that these actions may be-just like in humans-spontaneous and not linked to the current state (Corella et al., 2007; Raby et al., 2007). An opinion on this ability is also given by Suddendorf \& Corballis (2007). This research prompts deeper reflection on an aspect well highlighted by Hume, namely that the only scientifically provable ability is that of observing causality relations based on recurrence, i.e., on experience (Hume, 1987), a fact that has to be weighted in conjunction with observation, analysis, and memory.

${ }^{44}$ For aspects related to the ethology of animals, their moral traits, some cultural evolutions, cognition and metacognition, senses and consciousness, see Bateson \& Hinde (1976), Koehler (1976), Premack \& Woodruff (1978), Griffin (1984), Burghardt (1985), Alexander (1987), Byrne \& Whiten (1988), Eibl-Eibesfeldt (1989), Povinelli et al. (1990), Metcalfe \& Shimamura (1994), Runciman et al. (1996), Vauclair (1996), Dugatkin (1997), Boehm (1999; 2012), van Schaik et al. (1999), Zuckerman (1999), Brooks (2001), Suddendorf \& Whiten (2001), Griffin (2001), de Waal (2003; 2006), Bekoff (2003; 2007), Griffin \& Speck (2004), Herrmann \& Tomasello (2006), Moll \& Tomasello (2007), Gangestad \& Simpson (2007), Hardy (2009), van Riel \& Destrée (2009), Baumeister (2010), Couchman et al. (2010), Bourke (2011), Bowles \& Gintis (2011), Bonnie \& de Wall (2012), Beck (2013), de Waal et al. (2014), Andrews (2014).

${ }^{45}$ For the depth of behavioural traditions preserved by social means in animals other than humans, see Fragaszy \& Perry (2003), Laland \& Galef (2009).

${ }^{46}$ The development of the ability to communicate, for instance, does not imply hierarchisations as long as the forms that are already present possess equivalent degrees of complexity and efficiency. Language is a means of communication innate to living matter, the human language being only one of its forms of manifestation. Generated like any other function transformed into instrument, language becomes stable as an enacted instinct, and evolves under the stimulation of increasingly demanding social needs. Although very important in the development of humanity, language is only an amplifier, not a condition (Majid et al., 2004; Astington \& Baird, 2005; Fitch, 2010).

The narrative, as a form and as an informative act (Gottschall, 2012) is not exclusively human, the waggle dance of bees being another similar example (Beekman et al., 2015; Schürch \& Grüter, 2014), together with the behaviour of many species, in which some individuals produce and use technology, while others observe. Ritualization (which develops as a consequence of interactions with others), elaboration, manipulation, imagination, or patience-that is, the ability to differentiate between the stringency of the present and the prospect of the future (the bibliography on mental time travel is fairly rich and illustrates both positions: it is only possible in humans / multiple animal species possess this, but we only refer the reader to Clayton et al., 2003) - all are traits that have elaborated forms and roles in the world of other species. For a study of how human language is 
The answer given by Louis Leakey to his student, Jane Goodall, upon her discovery that chimpanzees are able to conceive and use tools, is representative for the way in which human beings, in general, relate to such matters. The phrase "We must now redefine man, redefine tool, or accept chimpanzees as human!" contains two acceptable alternatives on the one side of the disjunction, and threatens with a third, inadmissible one on the other side. It does not seem to encourage an effort towards understanding reality in itself, but towards finding a solution that would preserve the privileged status of the human being, since redefining either tool or man does not necessarily imply a better knowledge of either-but rather a narrowing of the spheres of notions-, and certainly not of the chimpanzee; it therefore does not generate progress on the path of knowledge ${ }^{47}$. In general, as science shows that man is not what ideologies claimed him to be, and that humankind certainly does not possess, in its integrality, the potential for what ideologies alleged that each individual of the species possesses, humanity abandons the bastions it built for itself, on the one hand retreating under increasingly narrower criteria but without clarifying the unknowns, and on the other hand not encompassing the thought of those philosophers who maintained, for instance, the lack of free will ${ }^{48}$.

A group of superior primates, or of crows $^{49}$ - which use tools, transmit knowledge and possess a culture, $\operatorname{count}^{50}$, solve problems, know, practice and transmit social and behavioural rules, take care of their future, etc. - cannot be considered as driven by instinct alone, if for the same actions the same concession is not made for the human being. Apart from the prejudice stemming from precarious anatomical differences and from the impossibility of knowing whether the individuals of other species do "think", there are no discriminating scientific criteria for one and the same action arisen in two different species ${ }^{51}$. At the same

understood by other animals, see Savage-Rumbaugh et al. (1993).

${ }^{47}$ Since then, it has been proven that other animals conceive, build, and use tools. The consequence has not been the redefinition of tools or of man, nor the classification of those animals as human, but only the expansion of human knowledge. This also means that such fears do not belong to scientific knowledge or to reason.

${ }^{48}$ Amongst the dissonant voices-treated as such in this regard-are Helvetius, Spinoza, Hume, Schopenhauer, and a thinker such as Stephen Hawking, who is not well known for his categorical statement "free will is just an illusion"; see, amongst others, James (1879), Bohr (1933), Wooldridge (1963), Nisbett \& Wilson (1977), Hofstadter (1982), van Inwagen (1983), Libet (1985), Searle (2005), Banks et al. (2006), Megill (2007), Gazzaniga (2011), Gregg (2012).

${ }^{49}$ Perhaps, after humans, crows are the best and most dedicated builders of tools; the youngsters learn by observation and imitation, and by trial and error, and the social system stimulates the vertical transmission and inhibits the horizontal one (N.B.). This learning is gradual, within a certain period of time (approximately a year), and the technological evolution is cumulative (Holzhaider et al., 2010).

${ }^{50}$ The concept of 'number' is so abstract that although the majority of people possess the ability to count and to make calculations, they are incapable of understanding the concept-even at a mediocre level-, their actions of "counting" and "computing" being merely a series of learned behaviours. This is not the only situation where a human being may know how to do something without actually understanding what it does, and without knowing what the essence of the concept and of reality is, a statement that also holds true for the most human attribute: language ("We know how to use a word to mean something and to refer to something. We know how to coin new words and to assign new meanings to them. We know how to create codes and artificial languages. Yet we do not know how we know how to do this, nor what we are doing when we do. Or rather, we know on the surface, but we do not know what mental processes underlie these activities, much less what neural processes are involved", Deacon, 1997). Considering the entire population of speakers of a natural language, a careful study would easily show that the majority of speakers use the language far beneath the level at which it is used by a minority of speakers, in that the former use language by emitting speech sounds rather than by articulating, and by signifying with an inventory of objects rather than by recreating concepts and relations. Beyond this consideration, however, it is remarkable that the majority of people use language in a rather rudimentary manner, both at a lexical-semantic and a grammatical and phonetic-phonological level. In other words, language functions within below-mediocre parameters in those complex compartments where language relates to thought, and its functioning at a phonetic level shows that the overwhelming majority of speakers remain under the weight of sensorial-motor habits, lacking the ability to control their phonation and conform to certain standards. This state is remarkably similar to that of other beings.

${ }^{51}$ Social and cognitive sciences know that different effects may emerge from similar or identical causes, and that similar or identical effects may be due to different or little related causes. Each time, however, there is a need for meticulous research - to find out what really happens, and what that process signifies within the reality in which it occurs, not within the mentality, 
time, since consciousness and memory are not knowns in the equation, they cannot be arguments for a presumed difference at the level of the action itself. In general, not understanding the others is not a proper basis for their judgement, classification, and definition (Deacon, 1997; Boesch, 2012; Beck, 2013) ${ }^{52}$.

Since reality - through the evidence it provides—is as binding as possible, such adjustments are operated at a conceptual — and especially linguistic - level by means of interpretation. Humans employ a fundamental survival strategy of the living world: the elimination from their own universe of anything seemingly hostile (potentially by casting it into oblivion). Syntagms constructed for this purpose seem to refine concepts, make fine distinctions, and observe reality in nuanced ways; in fact, they merely draw fictitious distinctions within a forged reality, creating apparently unconquerable positions, as part of a discourse and a mental effort that mimic or obstruct reality. At a linguistic level, one notices that the terminology referring to the human being is entirely anthropocentric, the terms that humankind created for itself being aimed at reflecting a special variety of reality. This is how one can explain the fact that terminology referring to other beings is doubled by that referring to humans, with the differences being much less scientifically- than ideologically-based. This situation does not result from scientific research, but from preconceptions that predate and determine the research, the conceptual level, and the terminology 53 .

If remarkably fine and precise "instincts" - the biochemistry of the nervous systems, the "biological mechanisms", or, more exactly, the result of the action of physical (mechanical, optical, thermodynamic, electrical, etc.) and chemical laws, manifested at a biological level-make animals what they are, it still has to be proven that humanity, in its entirety-having lost the habit of at least some of these instincts ${ }^{54}$ - has truly gained a superior attribute, able to elevate it from the sequence of all other animals, where it still is from a genetic point of view ${ }^{55}$. In fact, "rational humanity" refers, at most, to certain levels in the refined area of certain abilities, since: a) not all humans succeed in acquiring and possessing the same abilities in

imaginary, or human hermeneutics - in order to reach the knowledge of reality, not of a quod erat demonstrandum.

${ }^{52}$ Even more telling is that, starting from denying any common attributes shared with the human being, going through the successive acceptance of certain traits as being present in other animals, then as being defining for them, nowadays the evidence provided by research is accepted, but continues to be tempered by interpretations founded on different grounds. For instance, it may be accepted that animals have culture, but probably (less than half a century ago it was certain) they do not realize it since there is no proof of metarepresentation (Gruber et al., 2015). Beyond the fact that, in such cases, the refinement of conceptual contents is not real, such a statement (and one of the more reasonable at that) is in line with those who enumerate attributes belonging to the pinnacles of humanity, attribute them to the entire humanity, and then demand them from other primates. In fact, the similarities between the human being and other animals are so abundant and fundamental that for any attribute it is enough to carefully study humans, then some animals, in order to discover that the presumed differences do not exist, the peculiarities being only quantitative. For the confusions and disputes regarding some aspects of human consciousness, see Block (1995).

${ }^{53}$ For that matter, research on animals is quite often not aimed at knowing and understanding them in themselves or within the living world, but are indirect means of finding more about humans-with double-edged implications.

${ }^{54}$ As the human being acquires awareness (of itself and of the environment) - by acquiring the ability to store information, to compare data, and to correlate the results of its actions with experience and with the environment, according to the level of abilities it possesses-instincts are somewhat doubled, or the information that reaches them is subject to an additional "check" by a new instance. Without cancelling instincts or the neural pathways, the emergence of the neocortex (a material structure that developed relatively fast and at an accelerated pace) modified the effects of the interactions with the environment and generated new types of internal interactions, with the neural pathways becoming more complex, and the existence of self- and environmental-awareness generating acts with volitional appearance.

The conscious following (and even speculation) of the laws, through acts that do not harm them or prevent their action, leads to predictable results, intended based on-and suggested by-past experience; this, however, is not "control", but rather compliance with the very path upon which matter is forced by external constraints. The same (or even more accurate) results are obtained in the absence of awareness, when instincts are so finely-tuned that everything takes place in perfect order.

${ }^{55}$ Such instances give rise to questions such as: What exactly defines the affiliation to a species, if the morpho-physiological traits are demoted and replaced with psycho-social traits lacking rigorously verifiable grounds? Is the rigour of intra- and interspecies judgements the same? What are the traits that are automatically inherited by the descendant, and what are the traits 
the same degree, $\mathrm{b}$ ) those who do possess them are not entirely distinguished from the others, and from the point of view of the general traits of the species they do belong to a common (unique, genetically determined) class (Tomasello \& Call, 1997; Geary, 2005) ${ }^{56}$. The investment is not guaranteed, since the human being that acquires an ability does not constantly and necessarily use it for maintaining and acquiring behavioural patterns (Flinn, 1997; Deacon, 2012).

For various reasons, man tends to overemphasize his differences from other animals. These distinctions are neither old enough, nor stable enough, his biological basis remaining not only dominant but also exclusive. Regardless of the results of evolution at a cultural level, the human civilization is more fragile than the fundamental biological needs, since-even if humankind believes to have found the meaning of its existence in culture-its real existence takes place at a biological level (Morris, 1999). At the same time, the human being is not a "rational" one, unless this means that some humans, in certain situations, may make calculations and even exhibit behaviours according to certain principles deducted from previous experience or calculations, and which are already stored in memory (which has not only the ability to store, but also to correlate, process, and quickly access suitable answers). On the other hand, although based solely on the level of culture developed in other animals it cannot be inferred that they completely lack reason, the "instinct" or nature provided them with infallible means, often infinitely more accurate that those developed by human reason, through which they enter into optimal conjunctions with nature, adapt to the environment, and fulfil all their functions and activities as part of the environment and of nature.

There is probably more truth in the statement that, often, various other animals have intellectual, cognitive, and psycho-social abilities equal to many human individuals and groups-even integrated in societywhose humanity should not be asserted exclusively on morpho-physiological grounds. In the same way, the pinnacles of humanity cannot represent the entire species, and animals that exhibit "human" traits and have accomplishments of the same kind cannot be regarded as standing out of the normal sequence of the species, due to their contact with humans (either since animals imitate humans, or since humans interpret anthropocentrically $)^{57}$, and not due to differential evolutions within their species. The statement that human actions are, in general, on a superior level than those of animals, or that animal actions are on an inferior level than the same actions in humans, is yet to be proven ${ }^{58}$, in spite of the fact that between the two types of social organisms there are obvious qualitative differences.

forbidden to a species? Which mutations are stabilized? May traits and attributes be presumed? Can Aboriginals who have not constructed an Euclidean, Newtonian, or quantum system, and who do not use computers, be considered human? Are exalted attributes exclusively human, or are they just arbitrary distinctions within a set of common traits?

${ }^{56}$ For the evolutionary success of the human species, owing to its abilities of cultural accumulation and continuity, as well as to its propensity for sociality, presumably turned genetically coevolutive, see Dean et al. (2012).

${ }^{57}$ Anthropomorphism is a tactic employed by anthropocentrists by which they ignore or interpret actual facts or data, through which human abilities are required of animals, the realities and situations in question being reduced to an anthropocentric perspective (Morris, 1999; Keeley, 2004; Barrett et al., 2007; Boesch, 2012). Nevertheless, even though different from human societies - in that they lack both a social framework elaborated on moral-rational principles, and elevated intellectualbehavioural models present in some humans-, animal societies manage to attain average behaviours superior to those that may be noticed in some humans. See also Wrangham et al. (2006).

${ }^{58}$ Hence both Pascal's position and the entire debate on awareness warrant reconsideration in the context of altruism. To begin with, it should be clarified whether human actions can be the result of free will (a proportional rigorism would here require either a proof that there are realities outside determinism, or that the entire Universe is governed by the necessity of the fulfilment of a universal law, nothing being left to chance or not driven by necessity), that is, based on reasoning that does not exclusively originate in biological processes, primarily and ultimately determined by physics and chemistry (Miller et al., 2002; Linden, 2007; Merker, 2007; Shubin, 2008; Cochran \& Harpending, 2009; Lane, 2009; Damasio, 2010; Thagard, 2010; Calcott \& Sterelny, 2011; Gottschall, 2012; Morris, 1999; Preuss, 2012; Pross, 2012). The mere passing through awareness of thoughts and of other resultants of biological processes within the brain, in other words, the conscious realization, is a form of internal feedback, not of rational participation in the decision-making process. At the same time, the human mind struggles to devise experiments that could clearly prove or disprove the existence of self-awareness in other animals, the mirror 
The acquisition of the ability to refer to reality in linguistic terms (that is, the partial passage of reality from a sensorial-intuitive level to a linguistic level) using certain linguistic signs acquired by social means is considered a defining and quintessential human trait, believed to have triggered a range of developments that generated attributes considered exclusively human (Greenfield, 1991; Deacon, 1997; Hauser, 2000; Weber \& Depew, 2003; Hinton \& Nowlan, 1987, but also Kaznatcheev, 2014). Other primates may issue such references by vocalization, though not in a controlled way, but as a consequence of certain emotional states. Recently, a group of chimpanzees moved from the Netherlands to Scotland, faced with the situation of having to socially integrate themselves into the preexisting group, were capable of learning different "grunts" from those they already possessed in order to refer to already-known realities (Watson et al., 2015). In human terms, this is equivalent to learning a new language ${ }^{59}$. Because such a result contradicts the established knowledge, if these observations will be confirmed by future experiments, one might keep in $\operatorname{mind}^{60}$ that other primates also: a) have control of their vocal production and emission, these not being necessarily and always the direct effect of the presence of an emotional factor, but also the result of social learning (just like in humans); b) possess the necessary mental and physiological flexibility to learn new vocal fluxes. At the same time, the following question arises: setting aside the spatially erratic character of animal communities (families, clans, tribes), is the system of vocal fluxes used by a generation, within one and the same community, not transmissible to the next generation, albeit with inherent changes of a certain kind and within certain limits?

Until know, it has been sustained that: a) human intelligence is flexible, while that of other animals is specialized ${ }^{61}$; b) the tendency towards efficient and economical communication diversified the functions, making them more supple, with the evolution of human consciousness following the direction of its adaptability; c) the evolution of language was the primordial condition for conscious thinking, a distinctive trait from all other beings (Lakatos \& Janka, 2008).

It seems that the attributes through which humankind wishes to define itself as different from other animals are in fact much more common, with the differences being mostly of intensity or degree, and in no case essential ${ }^{62}$. The scientific research from an evolutionary perspective, starting from the material identity of all living things and following the evolution of the

test (Povinelli et al., 1993, 1997; Hyatt, 1998; Delfour \& Marten, 2001; Reiss \& Marino, 2001; Broom et al., 2009) and other similar experiments being more rudimentary than many of the instruments created by animals, and just as irrelevant as other human inventions. On the other hand, with the understanding that altruism is a constituent mechanism of the animal world, which is related to the nature of living matter, it would be worth reflecting on the belief that altruism passed through the filter of consciousness is superior to the "natural" or "instinctual" one characteristic to animals. Besides the obstacles discussed so far, there still are two questions to be answered: a) how unnatural or cultural can a product or subproduct of a natural product be? and b) how does the fact that one and the same effect (altruism) emerges or not from an action that has been brought into consciousness generate a hierarchical relation?

${ }^{59}$ For the change by evolutionary means of whale songs, and for the intra- and inter-individual variability, with dramatic changes in the songs that are not yet understood by humans, see Noad et al. (2000), Payne \& Payne (1985).

${ }^{60}$ Of course, experience teaches us that following the-already present-reactions that deny the accuracy, relevance, and correct interpretation of the observations, there will be intense intellectual efforts not to understand what actually happens, but to prove that humans must remain alone on the field of linguistic abilities, which-if unsuccessful—will be followed by others that will strive to show, for instance, that if this field is indeed a common one then humanity actually consists of something much deeper.

${ }^{61}$ In general, specialized individuals and groups are much less prone to acquiring abilities outside of the occupied niche, while those not specialized are opportunistic and exhibit exploratory tendencies.

${ }^{62}$ Recent research on the habitats and lives of animal communities (modelled on the study of humans) show that some functions are not exclusively linked to certain structures, that they preceded the appearance of our species, and that their development is the result of specialization rather than creation on the way. Thus, by revealing traits that were refused to animals, or that were not known to appear in them-and consequently considered exclusively human-, our picture of the dynamics of reality becomes more complete, the lack of understanding of animals turns into knowledge, and we surpass the mental and linguistic denial of the community and identity of attributes by recognizing them. 
phylogenetic tree from ribosomal RNA to the most evolved species, with the observation of their respective evolutionary branches and the development of the taxonomical, functional, etc. particularities of the entities, offers solid grounds for all sciences, placing human knowledge under the authority of reason and of its instruments, and leads to a deep understanding of reality, capable of supporting a conception that truly reflects it.

Just as evolution forges its way as it unfolds, without following predetermined paths, human knowledge is what emerges from scientific research and from proofs of reason based on the knowledge of material reality, not from dogmatic reflection or from assertions placed on the illusory ground of thesist constructions ${ }^{63}$.

\title{
8. Gene-culture coevolution ${ }^{64}$ (Nibil potest ordinari in finem aliquam nisi praexistat in ipso qua- dam proportio ad finem)
}

Any entity can be both element and structure, organism and environment, product and factor, etc., which indicates not only the hierarchisation and interdependency of material entities, but also their community. The particular way in which they evolve is by being subjected to adaptive processes resulting from interactions with the environment. The structures of an organism (from the most to the least restrictive meaning of the word) emerge and exist in correlation.

\begin{abstract}
We strongly stress the fact that only by looking at an organism in isolation can one talk about its interaction with the environment, as if they were two distinct entities, when, in fact, everything is environment, even this term being unsuitable as it is predicated on a separation made within a unitary reality. Organisms are products of the "environment", coadaptation and coevolution being the very condition for the existence of living matter, and being, in fact, a most natural process.

In fact, at the organic level, the properties of anorganic matter become functions, and the assimilative and adaptive actions through which the living matter ensures its existence (starting from the transformation of energy into "food") are interactional with the environment, therefore adaptive, reflecting the natural tendency to re-balance the "competitive" relation between organism and environment, which is a form of evolution.
\end{abstract}

Even though they may exhibit different degrees (and even elements) of separation and autonomy (probably exclusively in areas that do not directly affect the correlated organism or the superordinate system), this fact does not imply a formal isolation, a functional independence, autosufficiency, or autarchy. It is thereby not only natural, but also advantageous (that is, economical and efficient) for structuring processes to grow together and become mutually accommodated from the very beginning, evolution being a process of accommodated correlation and adjustment, from a single element, from a simple form, and under the control of a principle. Although important, the mere remark of the fact that living matter evolves is not enough for the profound understanding of this complex of processes.

\footnotetext{
${ }^{63}$ This attitude is not limited to the domains outside of science. In this aspect, the way of advocating and defending August Weismann's theory is exemplary (Bailey, 1894/2015).

${ }^{64}$ For this concept (introduced almost half a century ago) and its evolution, see Alper \& Lange (1981), Campbell (1988), Mellars \& Stringer (1989), Durham (1991), Wilson (1992), Thompson (1994, 2002, 2005, 2013), Soltis et al. (1995); Feldman \& Laland (1996), Pinker (1997), Klein \& Blake (2002), Heinrich \& McElreath (2003), Heinrich (2004), Lumsden \& Wilson (2005), Richerson \& Boyd (2005), Tomasello et al. (2005), Bell et al. (2009), Klein (2009), Cochran \& Harpending (2009), Gintis (2011, 2014), Laland \& Brown (2011), Boyd \& Silk (2012). The intensity with which this concept is supported varies from acknowledging it as a real resultant and factor of evolution, yet decoupled from the genetic factor, to the near elimination of the latter in a process almost as exaggerated as denying coevolution altogether. Often, the attempts to approach and discuss it seem rather tarnished by various stakes, rather than aiming to accurately reflect reality (see Lycett et al., 2007, and on the other hand Boesch, 2012; then Christiansen et al., 2009, 2011). A pertinent, high-quality analysis is undertaken by Flinn (1997).
} 
8.1. Evolution refers to a concept that-much like other term-concept pairs-captures a relevant and significant attribute of the process of becoming, though not precisely, and not enough. Evolution is a principle and a process which, due to the ways in which living matter is structured and interacts, manifests itself under the material form of coevolution ${ }^{65}$. The gene, the DNA, the components of organisms, and the organisms themselves and their communities all evolve through coevolution-the actual modality derived from their existential needs within the environment. Referring to the means of collaborative, accommodated (in fact, agonistic) interaction at the level of the living structures, coevolution also implies the consequence that its results may be correlated both at a structural and at a functional level. In other words, the direct, prime consequence of coevolution of matter subjected to normal interactions within an environment refers to the edification and adaptation of structures and to their continuous existence, the element on which the process is exerted being material, not ideal. The fact that functions exhibit correlations proportional to those of the structures from which they stem and whom they support is a consequence of material coevolution, and does not grant the functions any possibility for autonomous or (quasi-)independent evolution.

Just like physical and chemical entities and processes, biological entities and existence may be reversible or irreversible. Established by means obeying certain constraints with the force of law, and endowed with the ability to successively accomplish various functions, therefore hierarchically organized and developing an increasing multitude of types of potential, the structures of living matter may be destructurable or restructurable ${ }^{66}$, and their becoming can be either reversible or irreversible. Having to respond to their own existential needs, to their interactions with the environment (i.e., the structures of the superordinate ensemble to which an ensemble or organism belongs, and the conditions it exists in), and to the exercise of their functional attributes, structures evolve at the confluence of these three types of asynchronous requirements, in an interplay of concurrent but also motive forces. Therefore: a) the evolution of structures follows a spiral path arising from their own needs, and from the interactions with the environment and with the functions they develop, the latter, in turn, required by the (adaptive) interaction between structures and environment, on the one hand, and between themselves, on the other; b) the functional attributes, the adaptive capability, and the evolutionary possibilities of the structures are characteristic traits of the latter; c) structures contain the details of their own construction and configuration, as well as the potential of the functions whose basis they form; d) what is actually transmitted are the data on which structures are established; e) being a necessary process, their evolution also represents the evolution of their embedded potential; in other words, functions cannot be inscribed into genes ${ }^{67}$.

8.2. The gene-culture coevolution theory attempts to bypass this principle, holding that evolution does not occur exclusively by genetic means, but also by cultural ones, i.e., that not only do genes determine life, but that sedimented and transmitted culture is also apt to co-determine the genetic evolution. The observation that apparently lends support to this theory is that similar to how genes are transmitted and influence the emergence, development and behaviour of the biological material, culture is also transmitted and disseminated, influencing and determining — to a certain extent-the living matter. In competition with sociobiology, the gene-culture coevolution theory claims for itself a part of the factor of evolution, while in reality it takes to a different and seemingly safer level the attempt to maintain the distinction between humans and all other living organisms.

\footnotetext{
${ }^{65}$ Although in language one talks-somewhat analogously-about articulation, in the reality of speech it is not articulation, but coarticulation (Pușcariu, 1994) that exists.

${ }^{66}$ All attributes are considered within the framework of evolution and of maintaining the living existence, not necessarily of its class or rank.

${ }^{67}$ We leave aside the theories that discuss epigenetic inheritance (Baldwin, 1896; Osborn, 1897), situations such as that of the prion proteins (Prusiner, 1998), etc.
} 
Apart from issues raised by terminology_an uncomfortable obstacle, constant in all the fields where language is involved, and upon which many philosophers, even before Hume and Kant, often insisted-, the opinion supported by (but also supporting) this theory is that the human being possesses morphofunctional, cognitive-intellectual, cultural-spiritual, and psycho-affective traits that profoundly differentiate it from other beings, traits that have generated consequences and qualitative jumps in geometric progressions at the level of the species; furthemore, it holds that our species is capable of demoting or even supplanting the genetic factor (Kellogg \& Kellogg, 1933; Hockett, 1960; Lock, 1978; Premack \& Premack, 1983; Pinker, 1984; Pinker \& Bloom, 1990; Deacon, 1997; Hurford et al., 1998; Purpura, 2006; Premack, 2007, 2010; Penn et al., 2008; Butler \& Suddendorf, 2014).

It is indisputable that animals possess excellent or almost perfect "instincts", by virtue of which they function, maintain their vital cycles, autoregulate and adapt themselves. In the case of the simplest of beings, physical and chemical laws directly manifest themselves at a biological level. With an increasing degree of structural complexity, progressively more nuanced means of functioning and adaptation are accompanied by greater chances for error, with selection becoming more complex in its ways, instruments, and classes of effects. The interference between structures, functions, and the action of environments resulted in enhanced capabilities to evolve, under the condition of increasingly intricate types of competition, and differentiated by the fact that not all animals possess the genetic material necessary for the development of complex systems. Evolutionary processes in human beings led to a considerable increase in the ability to acquire adaptations, flexibility, and structural-functional specialization of communication, which triggered a massive leap (or several big leaps within a relatively short period of time). From this, the human being has come to possess both self-awareness and awareness of its environment. Based on certain indirect effects and on measurements and tests in humans, who possess only partial knowledge and who operate based on their own - that is to say, inadequate - criteria, the lack of self-awareness in animals is presumed without being clearly proven. Such a hypothesis, referring exclusively to humans, although seemingly a rather a priori ideaistic construction emitted by the human conscience, and not deducted from or imposed by reality, cannot be rejected de plano; nevertheless, it will only deserve to be granted the status of conclusion at the moment it follows from scientific research, not while it is both formulation and conclusion of what is to be proven; otherwise it remains nothing more than a desideratum, or a working hypothesis.

8.3. Communication is the means by which nature coordinates its evolution (Witzany, 2014), this process generating cooperation together with its counterpart, competition (Mead, 2003). Various forms of existence exert these attributes in their own ways, as determined by their evolutionarily acquired traits, in particular at the level of the species and of the community. Thought and behaviour, which constitute natural means of potentiating or stabilizing evolution, may propagate by imitation-possibly as a consequence of the intervention of certain determinants-and may become patterns, norms, and reproduced models, which holds true for all products and subproducts, either direct or indirect, of all living matter. It is difficult to prove whether through any such attribute, or any of its direct effects, differences in rank could be established within the animal kingdom. The transformation of the components of the environment, in conjunction with the evolution and the enactment of the organisms' potentiality, generated means of social organization and interaction, and also cognitive, technical, scientific, and even imaginary equipment - at first organized and adapted to the actual modalities and requirements imposed by the environment, then having adjacent developments-, which became generators of bioculture (Boyd, 2006).

Biological existence may generate intellectual and cultural-spiritual features. Through its potential attributes, matter organized at a physical, chemical, and biological level possesses abilities that are premises for its evolution, emendable-by contact with the self and with the environment which they can both respond to and model - in various ways and at increasingly expanded 
levels. Actions such as the mere manifestation within the environment, interaction, transitivity and communication, cooperation and coordination, sociality, reflection, etc., result in the development of the organisms, which thus acquire a further increased potential of exerting these attributes, in even more varied and potentiating ways ${ }^{68}$.

In an environment endowed with continuity, communication and community may broaden and deepen; in time, the cumulation, amplification, and durability bring along new needs and new expansions, a greater branching of communication, the strengthening of the community and hence even more continuity, and so forth (Boesch, 2012; Deacon, 2012). In the case of such a stable evolution, structural-functional traits may accumulate, stabilize, and coevolve with the behaviours and the instruments, in the context of the perpetuation of communication and community the traits thus acquired and stabilized (in fact, their lasting effects) being conserved, transmitted, and inherited, though without any of the guarantees offered by genetic inheritance.

8.4. The human being is a resultant of adaptive and evolutionary processes acting on the interactions between its genetic potential, its functional structure, and the demands of the environment; like any other being, it possesses the capability of progressively acquiring communication, socialization, and cognition abilities, all determined by genetics and by interactions, with the followed paths consolidating or restructuring acquisitions and behaviours (Maynard Smith \& Szathmáry, 1995).

Culture-which for anthropologists is a subject matter, for psychologists a learning process, and for biologists an adaptive process-may be material, ensuing from interactions with the environment and determining it, social, ensuing from interactions with other beings and expressing itself through a large network of social behaviours, or symbolic, representing norms, ideologies, institutions. Culture represents whatever is acquired, used, and transferred thus generating habits, the results of its evolution arising naturally from the evolution of matter from a biological perspective.

As it represents specific behavioural patterns acquired by social means and at a social level (Deacon, 2012), culture entails differences between social groups; in essence, there is no culture at the level of a species, only cultures. The production, acquisition, and transmission of cultural traits are determined by the social dimension of the living beings and stem from the adaptation process. In this way, a common basis in continuous adaptive becoming may be formed, which then models societies and the culture produced by them, giving rise to various habitual, behavioural, and mentalitary consequences.

Cultural traits can be learned in multiple ways (the mechanisms of cultural transmission being: observation, imitation, copying, practice, teaching and learning, evidently with the participation of the instinct ${ }^{69}$ ), the styles of learning differing between the various types of societies, and depending on the dominant type of culture, within a society and in time (Boesch et al.,2002; 2012). As culture is a phenotypical product, learning, in turn, is a type of phenotypical modification that participates to adaptation and that uses the environmental conditions in order to adjust the responses of the organism (Alvard, 2003). It further depends on the task at hand, and, in the complex and specific conditions of a society, occurs according to the possibility to practise what has been learned, while observing the resulting effects and their influence, and associating the mistakes with the costs involved. The dominant methods are trial and error in the material culture, influence in the social culture, and learning in the symbolic culture, which implicitly reflects and means that various types of learning produce different types of response at the level

\footnotetext{
${ }^{68}$ For example, the fundamental and primary role of language is not communication, but connection, then representationknowledge-communication. Fulfilled at basic level, these attributes amplified both the effects on language itself, and the effects at the individual and social level, augmenting the linguistic basis of the life and activity of the organ, of the function, and of the individual and social organisms, hence creating premises for development through amplification and expansions of all the organs and functions somewhat related to language.

Similarly, the ability to learn and teach generated both the direct surplus product of these actions, as well as the direct surplus of the processes themselves, augmenting the basis of both these and all other related processes.

${ }^{69}$ For the weight of cognition in imitation, see Heyes (1993), Bates \& Byrne (2010).
} 
of the various types of culture (Mead, 2012; Deacon, 2012).

Although the learning process and learning may be described, enclosing them in a definition is difficult due to the inventory of overtones in the realm of these notions. Nevertheless, one may show that learning is the product of genes, a response to the environmental demands through which the phenotype becomes equipped with an instrument that allows it to construct answers to the problems raised by the environment (Alexander, 1979). In this aspect, learning is not different from other flexible responses to the environment, its consequences and the actions it enables being - to the same extent-biological and involving the same chemical reactions, all products of evolution. In turn, the machinery for learning, the brain, is a product of natural selection, and is optimized to generate adaptive behaviours compatible with the demands of the environment (Flinn, 1997; Frith, 2007).

All these aspects hold true for non-human beings. Although equally connected to the environment, their feedback does not have the same effect on it, that is, their interaction with the environment occurs at another level, and within different parameters. Due to the fact that the reactions of organisms and the abilities they develop are proportional and related to the demands of the environment, non-human animals use more economical, more efficient, and less demanding means, as a consequence of evolutionary constraints, their evolution being, in a certain sense, an interplay of concurrent forces between action and reaction. The step from the transformation of reality into a tool to the manufacturing of a tool is dictated by need, and, initially, all that is required is memory. The fact that humans have the habit of inventing tools that can build even more complex tools, and thus arrive at complex products, is merely a response to the demands of the environment and to the ever more complex conditions of life.

Culture is an effect of phenotype and product of organic evolution, derives from selective pressures exerted by the environment-including competition between individuals, within a group, and between groups $^{70}$ - and has the ability to interact with other such traits and to disseminate itself (Alexander, 1989). By distinguishing the groups and helping them manage their relation with the environment, culture is a collective mental set of patterns and of cultural traits whose acquisition and transmission are determined by the social dimension and the relation with the environment (Whiten et al., 1999; Hohmann \& Fruth, 2003; Boesch, 2012; Deacon, 2012) ${ }^{71}$. This, however, does not mean that the results of cultural development may be genetically inherited, since culture does not have genes, and genes do not have culture.

8.5. In one way or another, everything that emerges at the phenotypical level, following the interaction between genes and the environment and as a result of the adaptability of living matter, is cultural; that is, it does not directly and exclusively stem from gene activity. This does not take such products from under the authority of the genes, since ontogenetically everything that exists is subject to the relation between genes and environment. The ways in which organic matter becomes equipped to give nuanced responses to the demands of the environment do not lead to a change in its material and genetic foundations, and do not promote an evolutionary path on which the foundations would become secondary while the results of their existence or evolution would become primordial or pattern-generating. Whatever and however large would the direct and indirect cultural surplus product of such a result would be, and even if it were defining for the current state of the human being (Passingham, 1982; Barnard, 2000; Clark, 2002; Pasternak, 2007), it ultimately and essentially ensues from the support of the material structure and its evolution, and is not an autonomous and inalienable given.

\footnotetext{
${ }^{70}$ Competition is a pressure force that enacts and develops unconscious adaptive capabilities to analyse, accommodate, learn, constitute, and develop mechanisms of adaptation (Flinn, 1997).

${ }^{71}$ For socioecological conditions, learning, intergroup variations, spreading of behaviours depending on age, kinship, behavioural effectiveness, etc., see Perry \& Manson (2003). For the evolution of social behaviour and inclusive fitness, see Hamilton (1964a; 1964b), Williams (1966; 1971), Bourke (2011), Gintis (2014).
} 
At the same time, in what concerns the mental phenomena (while admitting that some cultural phenomena are also mental), there are no reasons to individualize them or to consider them different from any other phenomenon of life. The brain, which is a neurobiological system, manifests itself through physical and electrochemical structures and processes along the entire variety of tasks it performs, whether it serves functions required for the survival and development of the organism itself, or its interactions with the environment (Gazzaniga, 1992).

Evolution within the framework of the social organism (Worms, 1895; Wilson, 2002) brings with it an increase in the degree of complexity of the organism-in order to respond to increasingly complex and varied demands, and in order to create wider possibilities for the organism to adapt and to continue its evolution-; the central stake is the increase in adaptability, with all other elements being means, instruments, and intermediate steps (Boesch, 2012; Deacon, 2012). The possibility for attributes and their effects to combine in unique ways, for particular uses and developments to emerge, and for cultural acquisitions to accumulate and develop, is able to generate individuals with advanced cognitive and cultural abilities. This, however, only occurs in so far as it is permitted by the genetic potential and by the principles that control its evolution. Since structures may only satisfy requirements within their own limits, and are not able to benefit from the help of functional acquisitions, which are secondary, a functional trait cannot be regarded in the same way as a genetic trait, as it does not possess the latter's inductive and autoreproductive abilities, and as it cannot break free from its genetic source and foundation.

Functions do not produce effects that would generate heritable changes in the structures. Regardless of the extent of involvement (through consecutive streams of consequences) of the intellectual and culturalspiritual dimensions in the development of an organism or of a community, they cannot be shown to possess a fundamental rank, that is, to have the effect of genes, or an effect on genes.

Traits are, of course, recursive, but only to the extent that they result from the essence of structures, a fact that can also be observed in that maintaining the conditions results in obtaining the results that naturally stem from those conditions, while a change of conditions leads to different results; the path to the results can only go through the structures, the only ones who bear within them their evolutionary potential.

The existence of two mechanisms of equal rank that have to manage one and the same reality (i.e., evolution, including aspects and derivatives thereof) is an impossibility from an evolutionary point of view, as long as between them there is no competition that would secure the domination of one over the other. Therefore, organic and cultural evolutions do not have a relation of equality, but one of filiation and inclusion, the latter stemming from the former and being engulfed by it. In this respect, coevolution appears as a step towards conquest - but also a way of recognizing the impossibility of the alleged mechanism of existing alone; it is merely a graft or a parasite masquerading as a symbiote.

As far as transmission is concerned (Boyd, 1985; Cavalli-Sforza \& Feldman, 1981), it should be noted that this phenomenon is one of dissemination or contamination, not of inheritance. As long as reality has varied forms of existence that reciprocally influence each other (by attraction, need, etc.), as long as there are vehicles, ways of hierarchisation, selection, and combination, transmission will be an active process. In fact, the only element that encompasses all of its principles, that is capable of plenarily manifesting itself and by itself, of autoreproduction, and of generating and driving all living organisms is the genetic material. The fact that, at some point, it may seem to lend away some of its attributes only speaks to its all-powerfulness, though not in the sense of the ability of generating an equal, but in that no evolutionary system is independent of the genetic one. Exempt from genetic laws, the evolution by cultural means and coevolution understood as an autonomous mechanism that negates the existence of a unique principle and of a unique source and generator of reality represent the triumph of the Lamarckian view, retreated from the concrete and physical domain to an obscure and immaterial one.

Under any aspect, from any perspective, and from any starting point, the primal, essential, fundamental, and indispensable character of the genetic factor is undeniable (Alexander, 1979). 
8.6. Functions are products able to evolve and propagate just like any other genetically-developed attribute of a biological entity, but they are not able to insulate themselves from the genetic universe and start their own lineage or contribute to one. Just like an acquired trait cannot be inherited, but can be closely reproduced by the genes that were inherited from the previous ones, functions are also not inheritable, since they are ephemerids that emerge at the confluence of the genetic material with the environment. What is inherited are parts of chromosomes, small genetic constellations even, which are able to produce traits and functions. It is not the function that is inherited, but the genetic material. The latter possesses capabilities and possibilities, which can develop within the framework of the organic structures (also developed by the genetic material), within the limits of its own constitution and potential. The unfolding of the entire organic and functional potential of the genetic material occurs in accordance to the directions of the environmental demands, possible oriented and constant efforts maximizing the potential, though not beyond the abilities of the genetic heritage. In this regard, learning is a form through which functional structures adapt to the peculiar interactions of a given organism with the environment, with possible modulations of a social nature.

Cultural traits may be transmitted with massive investments of energy, almost exclusively social, conscious and deliberately directed. In this cumbersome way and with unsystematic results ${ }^{72}$, they spread horizontally and vertically, within the same society or not, as memes, culturemes, etc. These, however, emerge exclusively at the confluence between a starting point identical with the actual and current state of the generations (and even of the intragenerational stages) and the effort directed towards the acquisition of part of the memory contained by tradition. The starting point is subject to perpetual movement, with on-the-fly additions and subtractions, with restructurations, reinterpretations, sedimentations, etc., which make it so unstable that it becomes crucial to know what is kept unchanged, what evolves coherently (deterioration being in the nature of organic matter), what is transmitted following this effort that devours its product. In its brief moment of existence, this conglomerate does not stop changing, and the stages of creation, development, enactment, selection, and transmission suffer inherent alterations, deflections, and interferences, even before the start of a new cycle in the next generation.

In spite of certain remnants that are maintained-by virtue of the involvement of natural selection $^{73}$, a true cultural selection being non-existent-it is difficult not to observe the similar situation in non-human animals. In social animals in general, it is possible for those who leave their community after having acquired its habits to be able to transmit those cultural elements to their new community, though this aspect is heavily dependent on prestige, as usually the identity of the inventor is more important than the utility of the invention (Kawamura, 1959; Horner et al., 2010). Although, for reasons pertaining to the specifics of human civilization, the trait of generality is dominant in humans, while the trait of locality is dominant in non-humans, in both cases one can observe-again, in very different degrees-the existence of communities established on multiple traditions, suffering interferences that affect the continuity of the block of traits at a given time ${ }^{74}$.

\footnotetext{
${ }^{72}$ Implicit transmission only occurs in genes, but even they are subject to natural selection.

${ }^{73}$ As phenotypical traits emerged from the needs of the organism having to solve concrete situations in contact with the demands of the environment, cultural elements can be retained in the mental and behavioural background, with the purpose of managing the relation with the reality of the environment.

74 "Only if a culture becomes too rigid as a result of its slavery to imitative repetition, or too daring and rashly exploratory, will it flounder (...). Those with a good balance between the two urges will thrive. We can see plenty of examples of the too rigid and too rash cultures around the world today. The small, backward societies, completely dominated by their heavy burden of taboos and ancient customs, are cases of the former. The same societies, when converted and 'aided' by advanced cultures, rapidly become examples of the latter. The sudden overdose of social novelty and exploratory excitement swamps the stabilising forces of ancestral imitation and tips the scales too far the other way. The result is cultural turmoil and disintegration. Lucky is the society that enjoys the gradual acquisition of a perfect balance between imitation and curiosity, between slavish, unthinking copying and progressive, rational experimentation" (Morris, 1999).
} 
Although social cognition is the basis of cultural evolution, neither does this process occur as a "cultural ratchet" (Tomasello, 1999; Hauser, 2001; Tennie et al., 2009), nor is it lacking in material support (Goodman \& Moffat, 2002), but quite the contrary (cf. Power, 1991; Gazzaniga, 1992; Povinelli, 2003; Deacon, 2012).

In fact, without learning at every generation, there is no possibility for the discoveries made in one generation to be accessible to subsequent generations, regress being not only possible, but necessary and ineluctable ${ }^{75}$.

Having obtained the means of transmitting the accumulated knowledge (be it elements, structure, content, value, and even the functioning of civilization, technology, science, as well as the methods and instruments of operating and developing them), the human being still has great difficulties in maintaining this process, particularly since the content, values, and means of functions are fleeting, on the one hand due to the rhythm of cultural development, which amplifies and diversifies itself almost immeasurably ${ }^{76}$, though mainly due to the fact that it does not possess the attributes of the genetic material.

At the natural level culture generates habits, at the scientific one it develops, at the ideological one it degrades; on neither does it autoreplicate (or is replicated) ${ }^{77}$ or create an entirely new type of organism.

\footnotetext{
${ }^{75}$ The basis of every community is given by genetics and by the interaction with the environment. This is common to all living beings, too few human communities possessing a third element, one legitimately capable of offering the attribute of humanity: the commitment, motivation, ideal, stake (Rădulescu-Motru, 1932, 1998; Mead, 1970; Deacon, 2012). Its ability to coalesce and unify can be observed in all communities that have built a materially and spiritually advanced civilization. Even in those, however, the attribute is not possessed in the same form by all individuals, some being natural creators, others being imitators. Perhaps one of the true distinctions between humans and other animals resides precisely in the former's ability to coalesce - through a mentally-elaborated linguistic discourse - the energies of others, who then voluntarily give up their natural liberties and obey a set of requirements in pursuit of an ideal goal.

${ }^{76}$ At the end of the $19^{\text {th }}$ century, the concept of 'social heredity' was conceived by the evolutionary psychologist J.M. Baldwin. According to him, within the framework of organic evolution, the structure and functions of organisms may incur modifications as a consequence of: a) environmental factors (radiations, various conditions and constraints), b) the functioning of the organism itself (usage develops in certain directions, lack thereof atrophies), c) adaptation by social imitation. The last element-defined from an ontogenic perspective, and also postulated for inferior biological forms-is called by the American psychologist and philosopher social heredity (Baldwin, 1897). The search for the factors of evolution has been an assiduous preoccupation of Neo-Darwinian scholars (sometimes even bringing forth factors of Neo-Lamarckian essence), which blurred their ranking, as their behaviour has been confused with their essence. A very important and just as common aspect is the adoption of terms in improper contexts from the point of view of the semantics imparted by the original author, an act that metaphorized those terms, with consequence at a conceptual level. See also Baldwin (1909). For the social transfer of information, tradition, culture, and cumulative culture, see Whiten et al. (2007a), Whiten \& van Schaik (2007).

${ }^{77}$ Here one may run into a small but specious confusion. The imitation, reproduction, and perpetuation of culturemes (customs, given names, behavioural patterns, etc.) do not stem from the autoreplication of that reality. They may appear alike to genes in so far as they are acquired, enter in use, produce effects, are transmitted faithfully or in a modified form. By reductio ad absurdum, a first implication would be that, were they to be transmitted and function like genes, this would imply the lack of free will, or that its exercise can be temporarily suspended, at least in those kind of situations. At the same time, memes would need their own material structure in order to replicate. The consequence could be admitted, but the requirement ought to be proven. Also, if one keeps in mind that such entities have the ability to autoreplicate, one still needs to prove the way, means, and mechanisms by which this occurs. In fact, memes are not living but animated entities, much like language: they do not possess the principle of existence within them, neither do they constitute an existential principle of living matter. They exist and function exclusively within living systems, but whom they cannot establish as a consequence of the plenary and autonomous manifestation of their own existence, though they can influence as a consequence alone of a somewhat parasitic relation (since symbiosis presumes a relation between two beings that are relatively equal in vitality). They are merely attributes and products-like any others-characteristic of an evolutionary stage of living matter, certain determinations that the gene creates for itself along its evolutionary path. Their relative novelty may make them seem current results and future causes of a qualitative jump, although they remain effects of the existential exercise of the aminoacids.
} 
8.7. Ultimately, the world of the human being is part of the physical world. It is established, exists, functions, and evolves upon the interactions that govern the physical, chemical, and biological world. In turn, the human being and the supreme organ, the human brain $^{78}$, together with all the effects of its evolved existence (language, thought, spirituality), are outflows of the physical world, resultants of physical, chemical, and biological processes occurring in the physical world, the human thought and behaviour emerging from the functioning of neurobiological mechanisms ${ }^{79}$ with the same physical and chemical basis. Regardless of the number and complexity of the evolutionary paths followed by its derivatives (culture, reason, etc.), Nature-which does not entrust vital decisions to reason, but to instincts alone (which cannot be summoned or blocked by reason or by any other process of the intellect)—will always maintain its rights and will, ultimately, prevail (Hume, 1987; Wright, 1995) ${ }^{80}$.

For this reason, the peculiar attributes of the human being-who possesses superior abilities in comparison to other animals - may be highlighted, but they do not separate it from the biological order of which it is part-both genetically and evolutionarily. Regardless of the novelty and the abilities of the term, the concept of coevolution has been forming in the human mind at least since classical antiquity, but the process itself belongs to the material world and to its evolutionary processes. Subordinated to the same principles and possessing both genes and culture, animals are equally subject to gene-culture coevolution (Rendell \& Whitehead, 2001), but through it they do not develop other evolutionary basis than the genetic one either. Regardless of the developments and ramifications it can produce, the only living reality that is self-contained and whose principles and laws stem directly from the universal physical laws is the gene: autoreproducible and autosufficient (Dawkins, 2001).

Beyond the organicity and integrity that characterize it, reality is varied and capable of responding to the most deforming requirements with the most creative solutions for survival and reproduction. In turn, unless it aims to be just an ideaistic, symmetrical, harmonious, esthetic, or ideologizant construction, the organism of science can only suffer from such separations-at any level they may occur-, because as they are not true to reality they generate breaches that produce destructurations and disfunctionalities.

If things are as such, there is no reason to conduct research on a certain species and its evolution according to distinct principles, methodologies, and instruments, which presumably stem from the essentially distinct character of that species, and not from the roots that generated that avenue of evolution, and which signify more than the specificities of that species within its genus, family, order, class, phylum, and kingdom ${ }^{81}$.

Since one does not encounter any kind of segregation within the animal kingdom - neither at the level of the order Primates, nor anywhere else-there is no need for a consequent segregation at the level of science ${ }^{82}$.

\footnotetext{
${ }^{78}$ Whose development is an adaptive response, by varied means, to the most diverse of problems, with the aim of obtaining the resources necessary for survival and reproduction (Geary, 2005).

${ }^{79} \mathrm{~A}$ study of the cellular and molecular mechanisms that lead to the creation of memory and the means to keep, lose, and recover it is presented by Kandel et al. (2014). For the entire matter, however, the return to origins is indispensable: Darwin (1875, p. 2-25, 26-127).

${ }^{80}$ Evolution does not determine behaviours by means of rational arguments, but by emotions generating a behaviour that has already been validated at an evolutionary level.

${ }^{81}$ Even in such a case, imagination and intuition advance at a faster pace than scientific research. It is necessary the for human sciences to wait for validations or corrections operated by the natural sciences, since-beyond any functions that may be acquired by the structures, keeping in mind that functional evolutions are predicated on material(-structural) evolutionsthe foundation of all reality is material.

${ }^{82}$ The very disciplines that attempt to specialize in the research of such aspects (anthropology, sociology, cognitive sciences, ethology, psychology, etc.) result from a splintering of biology.
} 


\section{The organicity of reality and of science (Mathesis universalis)}

The fundamental material particles obey certain laws tailored to certain principles, and they constitute the basic elements of which structures are formed. In turn, the latter may become constitutive elements of a superior level, which due to its ability to combine with other such structures-thus forming structures of even higher complexity-becomes an element at a new level, and so on, the capability for structural aggregation being universal.

As interactions and conjunctions generate new structures with increasing levels of complexity, the elements of reality (fundamental particles, whether material-fermions-or energetic-bosons-, hadrons, atoms; then: molecules, macromolecules, cells, tissues, organs, organisms, or planets, solar systems, galaxies, etc.) ${ }^{83}$ experience successive, hierarchical developments with new properties and functions, existentially engaged on more and more diversified and complex levels. The newly-developed structuralfunctional levels are governed by laws derived from the fundamental principles, the laws at any level being merely forms of manifestation of these principles. Similarly to structures and functions, laws are aggregated and based on the fundamental laws and principles: those that govern the conversion of energy to matter and the constitution of elementary material entities. As products of the fundamental interactions, the levels of progressive complexity do not constitute means of dividing reality. The apparent variety of structural levels is an efficient way of enacting a large gamut of interactional and functional valences, which thus unfolded reflect the potential of energy - manifested in material form - and the viability of structures and of levels, through adaptation and evolution.

Just like in the case of structures, the results of interactions, of combinations, and of the formation of a new level may lead not only to an increase in the number of properties or functions, but also to the emergence of qualitative results. Based on elements, the structures have forms and functions that sometimes surpass those of their components or the sum of their parts, that is, they produce entities with new forms and functions. These, however, result from (re)combinations, and are innovations, not creations. The fundamental principles are the same for all matter, and the laws based on them, although evolving, have a self-identical nucleus.

The way in which all these processes occur in reality is accurately reflected by physics, chemistry, biology, and by the relations between them, each assimilating the data procured by the others and-under the particular conditions of the given level and following their own contributions-enriching the knowledge of the common organism. At the level of the sciences above biology there are marked tendencies of avoiding this type of construction; these tendencies become stronger with increasing distance from the basic sciences, and the cognitive sciences suffer irresistible tendencies of asserting their autonomy at any cost.

The possibility of social, cognitive, and human sciences being taken over by (or reduced to) the natural ones may be perceived as a danger (Snow, 1993; Wilson, 1998) only if one forgets that the goal and stake of science is not autonomy, but knowledge. Apart from various shortcomings (regarding the accuracy of knowledge) that burden all sciences, (Nelson, 1992; Andrews, 2001; Crystall \& Foote, 2009; Jozefowiez et al., 2009; Beran et al., 2010) - a fact that is not prone to stimulating solitary enterprises - the real dangers are, on the one hand, for the Humanities to ignore or not assimilate the knowledge generated by the natural sciences ${ }^{84}$, and on the other

\footnotetext{
${ }^{83}$ The existence and complexity of the last two successions, regardless of their rank, have their foundation in the first, which is the base for any other succession.

${ }^{84}$ One of the frequently occurring tendencies is that of resorting, via some sort of equivalation, to literary or philosophical texts that seem to suggest things that science affirms. The appeal to such known facts and the reduction of the conclusions of natural sciences to them do not necessarily prove the lack of willingness to make an effort in the direction of acquiring knowledge offered by other sciences, but the lack of understanding that data obtained by rigorously scientific means cannot be replaced with the results of various intuitions or empirical observations, even if these are considered through the filter of logical reflection. Such knowledge remains approximate and closed-therefore unscientific-, as it feeds and leans only on itself.
} 
hand, for the fluidity of influx characterizing the natural sciences to lead them on paths unlit by the moral beacon.

A triple, perverse effect of the tendency towards autonomy is that sciences that follow after the fundamental triad: a) naturally tend to assimilate or contain certain principles and methods of the sciences before them-often based on an intuition of their utility rather than the understanding of organicity-, but while masking or stamping the borrowed elements; b) obstinately refuse any loan, perceiving the naturalness and normality of this act as an annihilating constraint (in fact, in both cases, the naturalness follows from the very nature of reality, to the extent that it remains the same regardless of how it is filtered by human consciousness); c) impose on sciences of similar rank constraints invented to stress the distinctions between them. What is shown, however, by the lesson of history, is that living organisms cannot be isolated, and any tendency towards either autarchy or evolution outside of the group leads to a dogmatic freeze.

For this reason, the distinctions between sciences should not be interpreted as grounds for autonomy or even specialization: they are not a reason for schism but for collaboration, since sciences are not to preoccupy with themselves, by themselves. Additionally, autonomy does not imply non-interference, which would be impossible and harmful in an objective and necessary way, as the scientific organism is communal, which means that no science should act on it in a way that would damage the very principles according to which the organism is structured and functions.

Natural sciences are particularly involved with the fundamental principles of reality, a basis on which cognitive sciences may search for the constitutive and functional principles of the social, mental-cognitive, linguistic, etc. processes. By analysing the reality with which they are in direct contact, all sciences participate to the synthesis of reality laid on the foundations deduced by the natural sciences through research at their levels of interest. The fundamental methods and instruments remain those of the natural sciences and of philosophy, adequately adjusted to the objects of the other sciences, i.e. to the realities with which they are concerned.

Research based on facts and experiments, on the one hand, and commentary, interpretation, and synthesis-grounded in rationality-, on the other, have always formed a bipolar entity from whose tension any sort of progress has emerged. The necessity of distinguishing them and of understanding each of their natures cannot lead to their separation - with the loss or forsaking of either of their exercise-, their nature requiring their co-presence and conjugated exercise. This may well be the premise for any form of real understanding and for any kindle of trust, even if the two processes alternate and do not occur in the same individuals. Usually, the absence of this conjunction characterize the ages in which the human mind changes its principles of operation, in which myths and phantasms return, and ideologies and particularisms exert their subduing action (Stenholm, 2011).

Examples of collaboration that can go all the way to the fusion of knowledge and to synthetic results $^{85}$, or of works that approach with all receptiveness and benevolence from a certain field, and become available to everyone (O'Bleness et al., 2012) are only beacons of hope, the vast

\footnotetext{
${ }^{85}$ Illustrative in this respect is Fitch (2010), a work that does not belong to a linguist (the author is an evolutionary biologist and cognitive scientist), but is a biolinguistic study of the evolution of language, from a Darwinian perspective, with elements of general and comparative linguistics, psycholinguistics, molecular genetics and neurology, based on a bibliography that is substantial in the quality of the consulted works; it is a study that - apart from numerous branches of biology and linguisticscalls into play contributions from other domains (mathematics, sociology, musicology, psychology, physics, ethology, etc.), which allows the author to articulate, in a coherent and organic manner, a complex image. The meaning of such an endeavour is, on the one hand, the need and capability to take from linguistics and other sciences certain data procured via the abovementioned bipolar entity, in order to construct an ample theory-which in itself reveals the unity of science-, and on the other hand, a certain level of desperation, often expressed by our colleagues in the natural sciences, who are either endlessly waiting for Godot to return from the depths of the Humanist field and share the results of his research, or watching how Icarus soars alone towards the untested heights. See also Hauser et al. (2002), Christiansen \& Kirby (2003), Bickerton (2007).
} 
majority of works choosing to either minimalize or completely ignore the natural and biological foundations, and overestimate the importance of the cultural factors.

Not only in this aspect, but naturally and from a strictly scientific perspective, it is unfathomable how, in general, when they do not ignore the results of research in anatomy, physiology, genetics, and in general in the natural sciences, the cognitive sciences seem to rather ignore the research that should have constituted the basis of any scientific assertion, as for instance is the case of Heyes (2012) or Lindahl (1997). Such writings seem to prefer, for example, interpretations that stem from the use of the mirror test, rejecting the certainties of anatomical dissections ${ }^{86}$, not understanding that discussion about functions, behaviours, sociality, the psychic, etc. lack a solid ground without the prior understanding of the functional and anatomo-physiological structures; regardless of how relevant the discussions about effects may be, they have no real basis unless one understand the primary causes. In fact, the lack of disposition to listen to those from other fields, whose preoccupations are-at most-regarded as mere curiosities, or as miscellaneous facts, is relevant from the standpoint of autism ${ }^{87}$ : some sciences consider that the evolution of matter was able to induce (in the case of the human being) such radical changes that the starting point and the operating principles are to be found exclusively in those sciences, or at even higher levels, and lean somewhat towards the function of "queen of sciences" 88.

The consequences arise naturally: amongst linguists, for instance ${ }^{89}$, the idea still circulates that the human larynx is an organ with peculiar characteristics owing to its adaptation for articulated speech $^{90}$; the preoccupation for the first moments of vocalization (justly delegated to other sciences, but without the subsequent recovery of the data provided by them) does not exceed the level of simple curiosity, and it is not understood that only knowledge of this aspect can allow the understanding of the ensuing ones. Only by resorting to biology can one-and not only linguists-gain fundamental insight into vocalized speech: many bird species have articulatory abilities superior to those of primates, acquired by imitation, just like in human children (Beckers et al., 2014) ${ }^{91}$. Its initiation, emergence, and functioning in the human species has purely biological causes-in response to evolutionary adaptations and pressures-, generated by bioevolutionary factors (Corballis, 2009; 2010). Bipedalism influenced respiration (MacLarnon \& Hewit, 1999) resulting in the reorientation of the laryngeal tract, allowing the soft palate to close off the nasal passage and the airway, and enabling the production of sounds in an economical and efficient manner (Savage-Rumbaugh et al., 1993); it constituted a major factor that stimulated the appearance of vocalized-articulated speech. The second important factor was genetic, spe-

\footnotetext{
${ }^{86}$ On the other hand, see MacLean et al. (2012).

${ }^{87}$ A statement such as "Bipedalism probably induced numerous adaptations at the level of all the components of the body, and generated consequent functional modifications. Given the pressure of the physical laws, the change of position led to restructurations of the skeletal system (of the limbs, the spine, the pelvis, etc.), the circulatory and respiratory systems, the acoustico-vestibular receptors, with direct or indirect implications on the relations within the limbs, the role of the anterior limbs, etc., and consequences regarding the use of tools, finding food and ensuring safety, achieving communication, language, thought" is not merely a curiosity or something that occurred long ago and with no implications in the present, or the image of an interesting mechanism that illustrates physical laws. Being basic in essence, such knowledge generates the understanding and explanation of a stratified progression of ranges of concrete situations, and therefore constitutes a vital piece of information.

${ }^{88}$ The selective accumulation of data from all sciences and their interpretation in a particular way is facilitated by the use of such an atemporal instrument as hermeneutics. The large collection of types of images and situations, in the absence of classification principles obeying scientific rigours, may stimulate the exercise of the dimensions and forms of consciousness, through the interplay of associative ricochets, a fact related to the preconceptive, teleologizant, and mythical mentality, which may well have auroral-intuitive or popularizing-plasticizant valences, thought it cannot be an instrument or process belonging to science, given its reductionist and associative-oneiric characteristics.

${ }^{89}$ We choose linguistics as an example as it is our main field of study, though linguistics is not the archetypal case.

${ }^{90}$ A relatively recent study (Fitch \& Reby, 2001) shows that those morphological traits and functional adaptations are fairly common among vertebrates, being used for vocalized communication established on the same functional bases.

${ }^{91}$ For the ability of primates to modify their vocal traits, see Weiss et al. (2014).
} 
cifically the appearance and stabilisation of the FOXP2 gene, which led to the restructuring of the cortico-basal ganglia circuits in the direction of acquiring and then refining and specializing the vocalization capability of the larynx (Falk, 1975; Fischer, 1998; Vargha-Khadem et al., 1998; Enard, 2002; Lieberman, 2002; Zhang et al., 2002; Bustamente et al., 2005; Lakatos \& Janka, 2008; Coop et al., 2008; Ackermann et al., 2014; Mattei, 2014; Meguerditchian et al., 2014; Zenon \& Olivier, 2014). Aside from the importantance of the exercise of acquisition (Bryant, 2014), the physical adaptation to vocalization was, probably, more important than the neural one (de Boer \& Perlman, 2014) ${ }^{92}$. In humans, one of the consequences of bipedalism and of the FOXP2 gene was the ability to emit finely-tuned sounds, with the consequence that the auditive organ acquired the capability to make similarly finely-tuned distinctions, which in turn entrained new changes in the direction of even finer distinctions, with consequences on the adaptability and evolution of acquired traits (i.e., sociality, language, thought, etc.). (Of course, regardless of what the initial impulse was and of which material element was the first to respond, once started, the process evolved in a coordinated manner ${ }^{93}$ ). In this way, linguists miss the starting point and its crucial character. The biological traits of the living being, resulting from its general configuration, produced the ability to emit at first involuntary, then voluntary sounds. The biological development ${ }^{94}$ of this result led to the functionalization of the capacity (the emitted sound becoming "useful" and efficient). From the entire set of evolutionary possibilities, the exercise of the ability in the new functional direction increased the chances of a specific bundle of biological responses, stimulating certain needs and developments. That is, organs become accommodated to this direction, and the satisfaction of demands in this way developed vocal abilities (which produced increasingly more accurate sounds) in correlation with auditive abilities (allowing the ear to discriminate sounds with a correspondingly increased accuracy). In a similar way, the experience of efficiently "reading" the natural symptom ${ }^{95}$ stimulated the appearance of the signal and then of the sign, the secondary effect of the symptom of an individual on another individual (additional food, consolation, prestige, privileges, etc.) stimulating the instinctual desire of the former to relive the beneficial state (first by obtaining the symptom, perhaps, in a natural way, then only its signal, and later on by replacing everything with a sign $)^{96}$.

\footnotetext{
${ }^{92}$ For the anatomo-physiological changes preceding vocalized-articulated speech, see Deacon (1997); for the precedence taken by phonation over prosodical and supraglottal articulation in both development and evolution of language, see Oller (2014).

${ }^{93}$ For the coevolution of motor and auditive abilities, for instance, as the basis of the perception of speech, see Lenti-Boero (2014).

${ }^{94}$ It is not "randomness" that promotes a certain aptitude, but the relation between demand and the ability to respond. On the lower steps of evolution, the types of perceived stimuli are scarcer, which holds true for the number of combinations between stimuli and the types of response. In a given situation, the chances for various directions of development are the same, and the possibilities of all to develop are significant. As these bundles of possibilities pass from potency to act and develop in a correlated way, the sheer number of possibilities of development in more and more directions generate strenuous competition, and an increasingly higher energy expenditure within increasingly more complex environmental conditions. At the superior levels of organism evolution, the chances for a possibility to prevail depend mostly on its collaboration with other possibilities, within a given environment and given the configurations and specializations of the organisms, and the abilities to efficiently answer a set of demands, while developing nuances useful to the existence of the organism and to its own capacity to evolve.

${ }^{95}$ Since-for reasons of economy and unity of matter-the organism develops less types of perceptible manifestations than the number of causes that generate them, the symptom does not always communicate one and the same type of information. Symptom, however, is an inexact and restrictive label, since in reality such a means of signalizing is complex, composed of various visual (for instance, a wound in itself, the blood, facial expressions and body language, limb movement, etc.), olfactory, and auditive messages, the analysers having to process data following the observation of the proportions and the ways in which the elements of the symptomatic complex are combined, obtaining a result which at first is to be compared with past results, and can then stand as basis for further comparisons. The symptom is processed reactively, instantaneously, and automatically; humans have the ability to intervene with awareness in this process, in which case experience (from similar situations, but also from other prior knowledge) is able to modulate the initial results.

${ }^{96}$ For the minor character of differentiations, the large gamut of possibilities, and the finesse of nuances, see Deacon (1997).
} 
At the same time, although closed frameworks may exhibit the apparent advantage and the certain comfort of movement within internal bounds, the collaboration between sciences safeguards against the natural alienations determined by isolation and autoreflexivity. The paths on which research advances may suffer various autopolenizations, homozigations, and closed loops, with the exclusive quartering into a single (synchronic or diachronic) perspective, by overlooking the true needs of the field and the methodological requirements, and by secluding itself from the benefits of knowing the evolution of the (closely or vaguely) connected domains. It is not a beneficial path, even simply because the lesson of living matter is the completely opposite one.

In the field of Romanian linguistics, for instance, several things occurred whose consequences remain manifest, and which affect and will continue to affect research.

The first is that syntheses preceded monographs. This is unnatural and harmful, since monographs pave the way for syntheses, and initial states necessarily and naturally require a consistent knowledge of the constitutive basis of reality. This issue has been partially remedied by those who understood the necessity for monographs and who corrected the deficiency ${ }^{97}$. Even then, however, the corrections have not always been effective, since syntheses have always been more influential, a fact that generated two other undesirable consequences: syntheses became the basis of teaching, learning, and even of monographs, and the valid information from syntheses has only been consolidated with the correct information from monographs after an additional (and still ongoing) effort. Whence follows the third undesirable consequence: this unsystematic and selective means of constructing syntheses has been reproduced in secondary research and in texts that dealt with aspects of limited extent.

The second is that there has never been a clear distinction between the analytic research of material aspects and the synthesis of complex topics. Erroneously, the lack of a solid theoretical and methodological basis was able to justify taking the liberty of operating inductions, often followed by the opinion that this effort may legitimize deductions. In this way, research concerned with the honest work of studying particular cases of limited extent has on the one hand been done with a lack of fundamental general and specialized knowledge, and on the other generated the idea that syntheses are a simple summation of interpretations operated on the results of the analysis of a particular case, a fact to which the researcher who procures these particular data should have implicit and natural rights.

The third fact stems from the attempt_made in good faith-of recovering a perspective that was too little or not at all mastered, a fact that led to incomplete and erroneous analyses and, evidently, to similar conclusions.

All these things led to the unravelling of the axiological paths and instruments, with the weakening of the natural hierarchies. The most dire consequence has been the ignorance of the necessity to answer the research needs of the domain. The accurate knowledge of the domain in its entirety offers true understanding of its hierarchical needs, and consequently of its priorities. The needs are based on the state of research, are real and imperative, and require the successive identification and choice of the topics that are most likely to be resolved, and that are most useful in the current state of the field. They stem from the level of theoretical knowledge and from the quality of the methods and instruments, in relation with the real possibilities for knowledge and research within the field. The research cannot be aimed at a question whose clarification needs, in turn, the clarification or at least the understanding of unknown, obscure, or insufficiently known, understood or clarified issues. Such a waste of energy evidently coincided with various structural and relational reconfigurations.

\footnotetext{
${ }^{97}$ Prior to that, scholars followed a different approach, and priority was given to answering a number of stringent problems in the field of linguistics; partially, however, they had underestimated the necessity for accurate monography, as shown by the unsystematic usage of those works on whose solid basis the observations and conclusions should have been grounded.
} 
For various reasons, the situation was correctly understood by numerous linguists, who chose the difficult but fruitful path; given, however, how actions recoil in science, it is significant thatapart from the fact that their effort was infinitely more demanding than if scientific issues had been laid on solid ground from early on, or at least corrected at an earlier stage-they faced at every step the danger of being mistaken, precisely because of the instability and speciousity of the preceding works they had to process. With the passage of time, for many varied causes, such a state of affairs becomes more and more difficult to correct, though one thing remains certain: the cost keeps increasing with each passing day.

This situation, rooted in the narrow context that generated the illusion that things can be solved with other types of efforts and in other ways, ought to be corrected.

Regardless of the level at which research is performed (a clear-cut issue, a number of correlated issues, or a complex topic) and regardless of the type of endeavour (analytic or synthetic, diachronic-prospective or retrospective-or synchronic), the need for profound theoretical knowledge in the field is paramount. In the same philosophical sense, there is a necessity to understand how other sciences report that reality is structured, functions, and evolves. Undoubtedly, the analysis of a grammatical conjunction does not require expertise in the natural sciences, but the true understanding of the roles of this connector implies the understanding of how other types of connectors exist and function in reality-a deep knowledge that most often is not acquired from one's own field, but, optimally, from the field in which that reality most genuinely reveals itself. This effort may then yield the ultimate reward: the stone laid in the edifice of linguistics will not undermine, but strengthen it.

The rethinking of science as an organism calls for a major change of conceptual and operational paradigms. First, each human science would start off its endeavour from the common set of knowledge and methods. Beyond the special aspects of each science, there are pieces of knowledge, truths, and particular aspects that are better revealed and observed by certain sciences (due to their specific objects, methods or approach, or since reality can be observed differently from that perspective). These can be communicated in linguistic forms accessible to others, the benefits spanning from the possibility to search, within one's own domain, the concrete forms of manifestation of that aspect, to the improvement of knowledge, with multiple ensuing consequences.

Second, each science can examine its own domain with its means of research and analysis, thus observing, isolating, refining specific aspects with characteristic instruments. This is the area in which the autonomy of each science is guaranteed and complete, the limits being set only by the dangers of mannerism, autoreflection, etc., and avoided by using the toolkit with which the researcher has descended into the depths of the cell, and by understanding the necessity to revert to the integrality of the organism.

In the third step, the processed products-now tried and true, clarified, and reconsidered from the common collaborative perspective-are brought back into the common space in order to serve the humanist synthesis, the one that constitutes the organism of science. In this way, research becomes a path rather than a space; a communal effort rather than a solitary endeavour.

\section{Conclusion}

As it reaches beyond the level of senses and intuition, the human knowledge of reality seeks meanings, symmetries, and harmonies which—if not found—are induced as idola tribus. Further along, it discovers the diversity of reality; the dominion of senses and passions over reason will classify and judge, will set stakes and express prejudice, idola specus, after which, purified and lucid in relation to its own endeavour and to reality itself, will seek in good faith the meanings of words, though it will only find their images, idola fori, and often, even before liberating itself from the terminological confusion, will institute the dogma, idola theatri (Bacon, 1957). Without being able to fully elude the dominion of any one of these categories, this form of existence of matter-the human being-, integrated in the kingdom and the 
phylum of which it is part, possesses still the resources of freeing itself of idols and of gaining access to science, in order to understand. It may well be that such a development can only occur by retracing the steps of the very reality which is to be understood; it definitely requires the harmonious collaboration of all the wheels and capabilities of science.

[Translated by Emanuel Gafton]

\section{Bibliography*}

Ackermann, M. \& Chao, L. (2004). Evolution of cooperation: two or one?, in “Current Biology”, Jan. 20, vol. 14, no. 2, p. R73-74, CrossRef.

Ackermann, H., Hage, St. R. \& Ziegler, W. (2014). Phylogenetic reorganization of the basal ganglia: A necessary, but not the only, bridge over a primate Rubicon of acoustic communication, in "Behavioral and Brain Sciences", Dec., vol. 37, no. 6, p. 577-604, CrossRef.

Alexander, R.D. (1979). Darwinism and Human Affairs, Seattle.

Alexander, R.D. (1987). The biology of moral systems, New York.

Alexander, R.D. (1989). Evolution of the human psyche, in Mellars, P. \& Stringer, C. (eds). The Human Revolution, Chicago, p. $455-513$.

Alper, J.S. \& Lange R.V. (1981). Lumsden-Wilson theory of gene-culture coevolution, in "Proceedings of the National Academy of Sciences of the U.S.A., June, vol. 6, no. 78, p. 3976-3979, CrossRef.

Alvard, M. (2003). The adaptive nature of culture, in "Evolutionary Anthropology", vol. 12, no. 3, p. 136-149, CrossRef.

Alves, Ch.J., Bertin, M. \& Clayton, N.S. (2013). Evidence of episodic-like memory in cuttlefish, in "Current Biology", Dec. 2, vol. 23, no. 23, p. R1033-1035, CrossRef.

Andrews, K. (2014). The Animal Mind: An Introduction to the Philosophy of Animal Cognition.

Andrews, P. (2001). The psychology of social chess and the evolution of attribution mechanisms: explaining the fundamental attribution error, in "Evolution and Human Behavior", Jan., vol. 22, no. 1, p. 11-29, CrossRef.

Astington, J. W. \& Baird, J. A. (ed.) (2005). Why Language Matters for Theory of Mind, Oxford, CrossRef.

Auersperg, A.M., Szabo, B., vom Bayern, A.M.P. \& Kacelnik, A. (2012). Spontaneous innovation in tool manufacture and use in a Goffin's cockatoo, in "Current Biology", Nov. 6, vol. 22, no. 21, p. R903-904, CrossRef.

Auersperg, A. M., von Bayern, A. M., Weber, S., Szabadvari, A., Bugnyar, T. \& Kacelnik, A. (2014). Social transmission of tool use and tool manufacture in Goffin cockatoos (Cacatua goffini), in "Proceedings of the Royal Society B: Biological Sciences", 3, Sept., vol. 281, no. 1793, CrossRef.

Bacon, Fr. (1957). Noul Organon, translated by N. Petrescu and M. Florian, București.

Bailey, L.H. (1894/2015). Neo-Lamarckism and Neo-Darwinism, in “The American Naturalist", vol. 28, p. 661-678, CrossRef; republished in „Diacronia”, no. 2, Jul. 17, 2015, art. A32, CrossRef.

Baldwin, J.M. (1896). A New Factor in Evolution, in "The American Naturalist", vol. 30, June, no. 354, p. 441-451; July, no. 355, p. 536-553, CrossRef.

Baldwin, J.M. (1897). Social and Ethical Interpretations in Mental Development, New York.

Baldwin, J.M. (1909). Darwin and the Humanities, Baltimore.

Baldwin, J.M. (1917). Development and Evolution, London.

Ball, Ph. (2015). Forging patterns and making waves from biology to geology: a commentary on Turing (1952) 'The chemical basis of morphogenesis', in "Philosophical Transactions of the Royal Society B: Biological Sciences", Mar. 6, vol. 370, no. 1666, CrossRef.

Bania, A., Harris, S., Kinsley, H. \& Boysen, S. (2008). Constructive and deconstructive tool modification by chimpanzees (Pan troglodytes), in "Animal Cognition", Jan., vol. 12, no. 1, p. 85-95, CrossRef.

Banks, W., Pockett, S. \& Gallagher, S. (2006). Does Consciousness Cause Behavior? An Investigation of the Nature of Intuition, Cambridge.

Barkow, J.H., Cosmides L. \& Tooby, J. (ed.) (1992). The adapted mind: Evolutionary psychology and the generation of culture, New York.

*Constituted along several years through constant and assiduous study—sometimes naturally, sometimes deliberately and methodically - of numerous texts from the domains and subdomains in question, the bibliography thus outlined reflects the topics of interest in this paper as well as our scruples, rigours, and qualms. The emergent opinion remains, however, ingrained by the specialized instruction in just one of the domains under discussion (which has relatively little weight within the framework of this study), by the multitude and variety of the domains involved, by the often contradictory nuances that arise from the reviewed texts, as well as by our own lack of understanding of numerous aspects. In an attempt to mitigate these shortcomings, we considered that a thorough documentation may offer knowledge and understanding, as well as the right to an opinion, and concurrent citations of different or even divergent points of view may prove useful in fleshing out a fair and balanced opinion. 
Barnard, A. (2000). History and Theory in Anthropology, Cambridge, CrossRef.

Barrett, L., Henzi, P. \& Rendall, D. (2007). Social brains, simple minds: does social complexity really require cognitive complexity?, in "Philosophical Transactions of the Royal Society B: Biology", Apr. 29, vol. 362, no. 1480, p. 561-575, CrossRef.

Bassler, B. L. \& Losick, R. (2006). Bacterially speaking, in "Cell”, Apr. 21, vol. 125, no. 2, p. 237-246, CrossRef.

Bates, L. \& Byrne, R. (2010). Imitation: what animal imitation tells use about animal cognition, in "Cognitive Sciences”, Sept.Oct., vol 1, no. 5, p. 685-695, CrossRef.

Bateson, P.P.G. \& Hinde, R.A. (ed.) (1976). Growing points in ethology, Cambridge.

Baumeister, R.F. (2010). The cultural animal: Human nature, meaning, and social life, Oxford, CrossRef.

Beck, J. (2013). Why we can't say what animal think, in "Philosophical Psychology", vol. 26, no. 4, p. 520-546, CrossRef.

Beckers, G.J., Berwick, R. K. \& Bolhuis, J.J. (2014). Comparative analyses of speech and language converge on birds, in "Behavioral and Brain Sciences", Dec., vol. 37, no. 6, p. 549-550, CrossRef.

Beekman, M., Makinson, J.C., Couvillon, M.J., Preece, K. \& Schaerf, T.M. (2015). Honeybeelinguistics-a comparative analysis of the waggle dance among species of Apis, in "Frontiers in Ecology and Evolution", CrossRef.

Bekoff, M. (2003). Consciousness and Self in Animals: Some Reflections, in "Zygon”, vol. 38, p. 229-245, CrossRef.

Bekoff, M. (2007). The Emotional Lives of Animals, New York.

Bell, A. V.; Richerson, P.J. \& McElreath, R. (2009). Culture rather than genes provides greater scope for the evolution of largescale human prosociality, in "Proceedings of the National Academy of Sciences of the U.S.A.", Oct. 20, vol. 106, no. 42, p. 17671-17674, CrossRef.

Bell, J.S. (1987). Speakable and unspeakable in quantum mechanics, Cambridge.

Ben-Jacob, E., Cohen, I. \& Gutnick, D.L. (1998). Cooperative organization of bacterial colonies: from genotype to morphotype, in "Annual Review of Microbiology", 52, p. 779-806, CrossRef.

Bentley-Condit, V.K. \& Smith, E.O. (2010). Animal tool use: current definitions and an updated comprehensive catalog, in "Behaviour", vol. 147, no. 2, p. 185, CrossRef.

Beran, M.J., Couchman, J.J., Coutinho, M.V.C., Boomer, J. \& Smith, D.J. (2010). Metacognition in Nonhumans: Methodological and Theoretical Issues in Uncertainty Monitoring, in "Trends and Prospects in Metacognition Research", CrossRef.

Bickerton, D. (1990). Language and Species, Chicago.

Bickerton, D. (2007). Language evolution: a brief guide for linguists, in "Lingua”, vol. 117, no. 3, p. 510-526, CrossRef.

Block, N. (1995). On a confusion about a function of consciousness, in "Behavioral and Brain Sciences”, June, vol. 18, no. 2, p. 227-247 (comentariile și răspunsurile p. 248-287), CrossRef.

Boehm, C. (1999). Hierarchy in the forest: The evolution of egalitarian behavior, Cambridge.

Boehm, C. (2012). Moral origins: The evolution of virtue, altruism, and shame, New York.

de Boer, B. \& Perlman, M. (2014). Physical mechanisms may be as important as brain mechanisms in evolution of speech, in "Behavioral and Brain Sciences", Dec., vol. 37, no. 6, p. 553-554, CrossRef.

Boesch, Ch. (2012). Wild cultures: A Comparison Between Chimpanzee and Human Cultures, Cambridge, CrossRef.

Boesch, Ch., Hohmann, G. \& Marchant, L. (ed.) (2002). Behavioural diversity in chimpanzees and bonobos, Cambridge, CrossRef.

Bohr, N. (1933). Light and Life, in "Nature”, Mar., 131, p. 421-423, CrossRef.

Bonner, J.T. (1980). The evolution of culture in animals, Princeton.

Bonnie, K.E. \& de Wall, F. B.M. (2012). Primate Social Origin and the Origin of Gratitude, in Emmons R. A. \& McCullough, M.E. (ed.), The Origin of Gratitude, Oxford Scholarship Online, CrossRef.

Bourke, A. F. G. (2011). Principles of Social Evolution, Oxford, CrossRef.

Bowles, S. \& Gintis, H. (2011). A Cooperative Species, Human Reciprocity and Its Evolution, Princeton, CrossRef.

Boyd, B. (2006). Getting It All Wrong: The proponents of Theory and Cultural Critique could learn a thing or two from bioculture, in "American Scholar", Sept. 1, vol. 4, no. 75, p. 18-30.

Boyd, R. \& Richerson, P.J. (1985). Culture and the evolutionary process, Chicago.

Boyd, R. \& Silk, J.B. (2012). How humans evolved, New York.

Boysen, S. T. \& Bertnson, G. G. (1989). Numerical competence in a chimpanzee (Pan troglodytes), in "Journal of Comparative Psychology, 103, p. 23-31, CrossRef.

Brooks, D. (2001). The social animal: The hidden sources of love, character, and achievement, New York.

Broom, D. M., Sena, H. \& Moynihan, K.L. (2009). Pigs learn what a mirror image represents and use it to obtain information, in "Animal Behaviour", vol. 78, no. 5, p. 1037-1041, CrossRef.

Brown, J.L. (1983). Cooperation - A Biologist's Dilemma, in "Advances in the Study of Behavior", 13, p. 1-37, CrossRef.

Bryant, G.A. (2014). The evolution of coordinated vocalizations before language, in "Behavioral and Brain Sciences", Dec., vol. 37, no. 6, p. 551-552, CrossRef.

Buchmann, St. \& Reppelier, B. (2006). Letters from the Hive: An Intimate History of Bees, Honey, and Humankind.

Bugnyar, T., Schwab, C., Schloegl, C., Kotrschal, K. \& Heinrich, B. (2007). Ravens judge competitors through experience with play caching, in "Current Biology", Oct. 23, vol. 17, no. 20, p. 1804-1808, CrossRef.

Burghardt, G.M. (1985). Animal awareness: Current perceptions and historical perspective, in "American Psychologist”, Aug., vol. 40, no. 8, p. 905-919, CrossRef. 
Bustamante, C.D., Fledel-Alon, A., Williamson, S., Nielsen, R., Hubisz, M.T., Glanowski, S., Tanenbaum, D. M., White, T.J., Sninsky, J.J., Hernandez, R.D., Civello, D., Adams, M.D., Cargill, M. \& Clark, A. G. (2005). Natural selection on proteincoding genes in the human genome, in "Nature", Oct. 20, vol., 437, no. 7062, p. 1153-1157, CrossRef.

Butler, D. \& Suddendorf, Th. (2014). Reducing the neural search space for hominid cognition: What distinguishes human and great ape brains from those of small apes?, in "Psychonomic Bulletin \& Review", June, vol. 21, no. 3, p. 590-619, CrossRef.

Byrne, R. \& Whiten, A. (ed.) (1988). Machiavellian intelligence: social expertise and the evolution of intellect in monkeys, apes and humans, Oxford.

Calcott, B. \& Sterelny, K. (2011). The major transitions in evolution revisited, Cambridge, CrossRef.

Camazine, S., Deneubourg, J.L., Franks, N., Sneyd, J., Theraulaz, G. \& Bonabeau, E. (2001). Self-Organization in Biological Systems, Princeton.

Campbell, B. (1988). Human evolution: An Introduction to Man's Adaptations, New York.

Campbell, B. G. (ed.) (1972). Sexual selection and the descent of man, Chicago.

Carroll, J., McAdams, D. P. \& Wilson, E. O. (ed.) (2015). Darwin's Bridge: Uniting the Sciences and Humanities, Oxford.

Cavalli-Sforza, L.L. \& Feldman, M.W. (1981). Cultural transmission and evolution: A quantitative approach, Princeton, New Jersey.

Cheke L. G., Bird C.D. \& Clayton, N.S. (2011). Tool-use and instrumental learning in the Eurasian jay (Garrulus glandarius), in "Animal Cognition", May, p. 441-455, CrossRef.

Choe, J. K. \& Crespi, B.J. (ed.) (1997). The Evolution of Social Behavior in Insects and Arachnids, Cambridge.

Christiansen, M.H. \& Kirby, S. (2003). Language Evolution, Oxford, New York, CrossRef.

Christiansen, M.H., Chater, N. \& Reali, F. (2009). The biological and cultural foundations of language, in "Communicative \& Integrative Biology", May-June, vol. 2, no. 3, p. 221-222, CrossRef.

Christiansen, M.H., Reali, F. \& Chater, N. (2011). Biological Adaptations for Functional Features of Language in the Face of Cultural Evolution, in "Human Biology", Apr., vol. 83, no. 2, p. 247-259, CrossRef.

Clark, M.E. (2002). In Search of Human Nature, London, New York, CrossRef.

Clayton, N.S. (2007). Planning for the future by western scrub-jays, in "Nature", Febr. 22, vol. 445, no. 7130, p. 919-921, CrossRef.

Clayton, N.S., Bussey, T.J. \& Dickinson, A. (2003). Can animals recall the past and plan for the future?, in "Nature Reviews Neuroscience", Aug., 4, p. 685-691, CrossRef.

Cochran, Gr. \& Harpending, H. (2009). The 10,000 year explosion: How civilization accelerated human evolution, New York.

Coop, G., Bullaughey, K., Luca, F. \& Przeworski, M. (2008). The Timing of Selection at the Human FOXP2 Gene, in "Molecular Biology and Evolution", Apr. 15, vol. 25, no. 7, p. 1257-1259, CrossRef.

Corballis, M.C. (2009). The evolution of language, in “Annals of the New York Academy of Sciences”, Mar., 1156, p. 19-43, CrossRef.

Corballis, M.C. (2010). Mirror neurons and the evolution of language, in “Brain and Language”, Jan., vol. 112, no. 1, p. 25-35, CrossRef.

Correla, S.P.C., Dickinson, A. \& Clayton, N.S. (2007). Western scrub-jays anticipate future needs independently of their current motivational state, in "Current Biology", May 15, vol. 17, no. 10, p. 856-861, CrossRef.

Couchmann, J.J., Coutinho, M.V.C., Beran, M.J. \& Smith, J.D. (2010). Beyond Stimulus Cues and Reinforcement Signals: A New Approach to Animal Metacognition, in "Journal of Comparative Psychology”, vol. 124, no. 4, p. 356-368, CrossRef.

Crespi, B.J. (2001). The Evolution of Social Behavior in Microorganisms, in “Trends in Ecology \& Evolution”, Apr. 1, vol. 16, no. 4, p. 178-183, CrossRef.

Crown, C., Laland, K. \& Krause J. (ed.) (2011). Fish Cognition and Behavior (Fish and Aquatic Resources), Wiley-Blackwell, CrossRef.

Crystall, J.D. \& Foote, A.L. (2009). Metacognition in Animals, in "Comparative Cognition \& Behavior Reviews", 4, p. 1-16, CrossRef.

Csibra, G. \& Gergely, G. (2009). Natural pedagogy, in “Trends in Cognitive Sciences”, vol. 13, no. 4, p. 148-153, CrossRef.

Czárán, T. \& Hoekstra, R.F. (2009). Microbial communication, cooperation and cheating: quorum sensing drives the evolution of cooperation in bacteria, in "PLoS One", Aug. 17, vol. 4, no. 8, e6655, CrossRef.

Dall, S. R.X., Giraldeau, L.-A., Olsson, O., McNamara, J.M. \& Stephens, D. W. (2005). Information and its use by animals in evolutionary ecology, in "Trends in Ecology \& Evolution”, Apr., vol. 20, no. 4, p. 187-193, CrossRef.

Damasio, A.R. (2010). Self comes to mind: Constructing the conscious brain, New York.

Darwin, Ch. (1875). The Descent of Man, and selection in relation to sex, new edition revised and augmented, New York.

Dawkins, R. (2001). Gena egoistă [The Selfish Gene], translated by D. Crăciun, București.

Dawkins, R. (2009). Ceasornicarul orb [The Blind Watchmaker], translated by S. Mudava, București.

Deacon, T. W. (1997). The Symbolic Species: The Co-evolution of Language and the Human Brain, New York.

Deacon, T.W. (2012). Incomplete Nature: How Mind Emerged from Matter, New York.

Dean, L. G., Kendal, R. L., Schapiro, S.J., Thierry, B. \& Laland, K. N. (2012). Identification of the Social and Cognitive Processes Undelying Human Cumulative Culture, in "Science", Mar. 2, vol. 335, no. 6072, p. 1114-1118, CrossRef.

Degler, C.N. (2011). In Search of Human Nature: The Decline of Darwinism in American Thought, Oct., Oxford Scholarship 
Online, CrossRef.

Delfour, F. \& Marten, K. (2001). Mirror image processing in three marine mammal species: killer whales (Orcinus orca), false killer whales (Pseudorca crassidens) and California sea lions (Zalophus californianus), in "Behavioral Processes", Apr., vol. 53, no. 3, p. 181-190, CrossRef.

Dobzhansky, Th. (1973). Nothing in Biology Makes Sense except in the Light of Evolution, in “The American Biology Teacher”, Mar., vol. 35, no. 3, p. 125-129, CrossRef.

Dubern, J. \& Diggle, St. P. (2008). Quorum sensing by 2-alkyl-4-quinolones in Pseudomonas aeruginosa and other bacterial species, in "Molecular BioSystems", Sept., vol. 9, no. 4, p. 882-888, CrossRef.

Dugatkin, L.A. (1997). Cooperation among animals: An evolutionary perspective, New York.

Durham, W. (1991). Coevolution: Genes, culture and human diversity, Stanford.

Eibl-Eibesfeldt, I. (1989). Human ethology, New York.

Emery, N.J. \& Clayton, N.S. (2004). The mentality of crows: convergent evolution of intelligence in corvids and apes, in "Science", Dec. 10, vol. 306, no. 5703, p. 1903-1907, CrossRef.

Emery, N.J. \& Clayton, N.S. (2008). Imaginative scrub-jays, causal rooks, and a liberal application of Occam's aftershave, in "Behavioral and Brain Sciences", Apr., vol. 31, no. 2, p. 134-135, CrossRef.

Enard, W., Przeworski, M., Fisher, S.E., Lai, C.D.L., Victor Wiebe, V., Kitano, T., Monaco, A. P. \& Paabo, S. (2002). Molecular evolution of FOXP2, a gene involved in speech and language, in "Nature", Aug. 22, vol. 418, p. 869-872, CrossRef.

Falk, D. (1975). Comparative Anatomy of the Larynx in Man and the Chimpanzee: Implications for Language in Neanderthal, in "American Journal of Physical Anthropology", 43, p. 123-132, CrossRef.

Feldman, M.W. \& Laland, K.N. (1996). Gene-culture coevolutionary theory, in “Trends in Ecology \& Evolution”, Nov., 11, p. 435-457, CrossRef.

Fischer, S.E., Vargha-Khadem, F., Watkins, K.E., Monaco, K.E. \& Pembrey, M.E. (1998). Localisation of a gene implicated in a severe speech and language disorder, in "Nature Genetics", Feb., vol. 18, no. 2, p. 168-170, CrossRef.

Fitch, W.T. (2010). The Evolution of Language, Cambridge, CrossRef.

Fitch, W.T. \& Reby, D. (2001). The descended larynx is not uniquely human, in "Proceedings of the Royal Society B", Aug. 22, vol. 268, no. 1477, p. 1669-1675, CrossRef.

Fitch, W.T., Huber, L. \& Bugnyar, T. (2010). Social cognition and the evolution of language: constructing cognitive phylogenies, in "Neuron", Mar. 25, vol. 65, no. 6, p. 795-814, CrossRef.

Flinn, M.V. (1997). Culture and the evolution of the social learning, in "Evolution and Human Behavior", Jan., vol. 18, no. 1, p. 23-67, CrossRef.

Foster, K. R., Parkinson, K. \& Thompson, Ch. R.L. (2007). What can microbial genetics teach sociobiology?, in "Cell”, Feb., vol. 23, no. 2, p. 74-80, CrossRef.

Fouts, R.S. (1973). Acquisition and testing of gestural signs in four young chimpanzees, in "Science", vol. 180, no. 4089, p. 978980, CrossRef.

Fragaszy, D. M. \& Perry, S. (ed.) (2003). The Biology of Traditions: Models and Evidence, Cambridge, CrossRef.

Frith, C. (2007). Making up the mind: How the brain creates our mental world, Oxford.

Furlong, E.E., Boose, K.J. \& Boysen, S. (2008). Raking it in: the impact of enculturation on chimpanzee tool use, in "Animal Cognition", vol. 11, no. 1, p. 83-97, CrossRef.

Gangestad, St. W. \& Simpson, J.A. (ed.) (2007). The evolution of mind: Fundamental questions and controversies, New York, London.

Gardner, R.A., Gardner, B. T. \& van Cantfort, T.E. (1989). Teaching Sign Language to Chimpanzees, Albany.

Gazzaniga, M.S. (1992). Nature's Mind: Biological Roots of Thinking, Emotions, Sexuality, Language and Intelligence, New York.

Gazzaniga, M.S. (2011). Who's in Charge? Free Will and the Science of the Brain, New York.

Geary, D.C. (2005). The origin of mind: Evolution of brain, cognition, and general intelligence, Washington.

Gintis, H. (2011). Gene-culture coevolution and the nature of human sociality, in "Philosophical Transactions of the Royal Society B: Biological Sciences", 366, p. 878-888, CrossRef.

Gintis, H. (2014). Inclusive fitness and the sociobiology of the genome, in "Biology \& Philosophy”, July, vol. 24, no. 4, p. 477-515, CrossRef.

Gloag, E.S., Turnbull, L. \& Whitchurch, C. B. (2015). Bacterial Stigmergy: An Organising Principle of Multicellular Collective Behaviours of Bacteria, in "Scientifica", CrossRef.

Goodall, J. (1964). Tool-using and aimed throwing in a community of free-living chimpanzees, in "Nature", vol. 201, no. 4926, p. 1264-1266, CrossRef.

Goodall, J. (2010). In the Shadow of Man, Boston, New York.

Goodman, M. \& Moffat A.S. (ed.) (2002). Probing Human Origins, Cambridge.

Gordon, D.M. (2010). Ant Encounters: Interaction Networks and Colony Behavior, Princeton, CrossRef.

Gottschall, J. (2012). The storytelling animal: How stories make us human, Boston.

Greenfield, P.M. (1991). Language, tools and brain. The ontogeny and phylogeny of hierachically organized sequential behaviour, in "Behavioral and Brain Sciences", Dec., vol. 14, no. 4, p. 531-595, CrossRef. 
Gregg, D.C. (2012). Free Will and Consciousness: A Determinist Account of the Illusion of Free Will, Plymouth.

Griffin, D. R. (1984). Animal Thinking, Cambridge, London.

Griffin, D. R. (2001). Animal Minds: Beyond Cognition to Consciousness, Chicago.

Griffin, D. R. \& Speck G. B. (2004). New Evidence of Animal Consciousness, in “Animal Cognition”, Jan., vol. 7, no. 1, p. 5-18, CrossRef.

Gruber, Th., Zuberbühler, K., Clément, F. \& van Schaik, C. (2015). Apes have culture but may not know that they do, in "Frontiers in Psychology”, Feb., vol. 6, art. 91, CrossRef.

Guttridge, T.L., Myrberg, A.A., Porcher, I.F., Sims, D. W. \& Krause, J. (2009). The role of learning in shark behaviour, Dec., vol. 10, no. 4, p. 450-469, CrossRef.

Guttridge, T.L., van Dijk, S., Stamhuis, E.J., Krause, J., Gruber, S.H. \& Brown, C. (2013). Social learning in juvenile lemon sharks, Negaprion brevirostris, in "Animal Cognition", Jan., vol. 16, no. 1, p. 55-64, CrossRef.

Guttridge, T.hspL. \& Brown, C. (2014). Learning and memory in the Port Jackson shark, Heterodontus portusjacksoni, in "Animal Cognition", Mar., vol. 17, no. 2, p. 415-425, CrossRef.

Hagen, S.J. (ed.) (2015). The Physical Basis of Bacteria Quorum Communication, Gainesville, CrossRef.

Hamilton, W.D. (1964a). The genetical evolution of social behaviour. I, in "Journal of Theoretical Biology", July, vol. 7, no. 1, p. 1-16, CrossRef.

Hamilton, W.D. (1964b). The genetical evolution of social behaviour. II, in "Journal of Theoretical Biology", July, vol. 7, no. 1, p. 17-52, CrossRef.

Hammerstein, P. (ed.) (2003). Genetic and Cultural Evolution of Cooperation, MIT.

Hardy, S. B. (2009). Mothers and others: The evolutionary origins of mutual understanding, Cambridge.

Hare, B., Call, J., Agnetta, B. \& Tomasello, M. (2000). Chimpanzees know what conspecific do and do not see, in "Animal Behaviour", Apr., vol. 59, no. 4, p. 771-785 (CrossRef.

Hare, B., Call, J. \& Tomasello, M. (2006). Chimpanzees deceive a human competitor by hiding, in “Cognition”, Oct., vol. 101, no. 3, p. 495-514, CrossRef.

Hauser, M. D. (2000). The Evolution of Communication, MIT.

Hauser, M.D. (2001). Wild Minds: What Animals Really Think, New York.

Hauser, M.D., Chomsky, N. \& Fitch, W.T. (2002). The Faculty of language: What Is It, Who Has It, and How Did It Evolve?, in "Science", Nov. 22, vol. 298, no. 5598, p. 1569-1579, CrossRef.

Heinrich, J. (2004). Cultural group selection, coevolutionary processes and large-scale cooperation, in "Journal of Economic Behavior \& Organization", 53, p. 3-35, CrossRef.

Heinrich, J. \& McElreath, R. (2003). The Evolution of Cultural Evolution, in "Evolutionary Anthropology", May 19, vol. 12, no. 3, p. 123-135, CrossRef.

Herrmann, E. \& Tomasello M. (2006). Apes' and children's understanding of cooperative and competitive motives in a communicative situation, in "Developmental Science", vol. 9, no. 5, p. 518-529, CrossRef.

Herrmann, E., Wobber, V. \& Call, J. (2008). Great Apes' (Pan troglodytes, Pan paniscus, Gorilla gorilla, Pongo pygmaeus) understanding of tool functional properties after limited experience, in "Journal of Comparative Psychology", vol. 122, no. 2, p. 220-230, CrossRef.

Heyes, C.M. (1993). Imitation, culture and cognition, in “Animal Behavior”, Nov, vol. 5, no. 46, p. 999-1010, CrossRef.

Heyes, C.M. (1994). Social learning in animals: categories and mechanisms, in "Biological Reviews", May, vol. 69, no. 2, p. 207231, CrossRef.

Heyes, C.M. (2012). Grist and mills: on the cultural origins of cultural learning, in "Philosophical Transactions of Royal Society B", Aug., vol. 367, no. 1599, p. 2181-2191, CrossRef.

Hinton, G.E. \& Nowlan, S.J. (1987). How learning can guide evolution, in “Complex Systems”, vol. 3, no. 1, p. $495-502$.

Hobaiter, C. \& Byrne, R. W. (2011). The gestural repertoire of the wild chimpanzee, in “Animal Cognition”, Sept., vol. 14, no. 4, p. 745-767, CrossRef.

Hochner, B., Shomrat, T. \& Graziano, F. (2006). The Octopus: a model for a comparative analysis of the evolution of learning and memory mechanisms, in "Biology Bulletin", 210, p. 308-317.

Hockett, C. (1960). The origin of speech, in “Scientific American”, vol. 203, no. 3, p. 88-96, CrossRef.

Hofstadter, D.R. (1982). Can creativity be mechanized?, in "Scientific American”, Sept., vol. 247, p. 20-29.

Hohmann, G. \& Fruth, B. (2003). Culture in Bonobos? Between-species and within-species variation in behavior, in "Current Anthropology”, Aug.-Oct., vol. 44, no. 4, p. 563-571, CrossRef.

Holzhaider L.C., Hunt, G. R. \& Gray, J.D. (2010). Social learning in New caledonian crows, in "Learning \& Behavior", Aug., vol. 30, no. 3, p. 206-219, CrossRef.

Horner, V., Proctor, D., Bonnie, K.E., Whiten, A. \& de Waal, F. B.M. (2010). Prestige affects cultural learning in chimpanzees, in Public Library of Science one, May 19, vol. 5, no. 5, e10625, CrossRef.

Hölldobler, B. \& Wilson, E. O. (1990). Ants, Harvard.

Hölldobler, B. \& Wilson, E. O. (2009). The Superorganism: the Beauty, Elegance, Strangesness of Insect Societies.

Hume, D. (1987). Cercetare asupra intelectului omenesc [An Enquiry Concerning Human Understanding], translated by M. Flonta, A.-P. Iliescu and C. Ioniță, București. 
Hunt, G. R. (1996). Manufacture and use of hook-tools by New Caledonian crows, in "Nature", Jan., vol. 379, no. 6562, p. 249251, CrossRef.

Hunt, G. R. \& Gray, R.D. (2003a). The crafting of hook tools by wild New Caledonian crows, in "Proceedings of the Royal Society of london, Series B", Feb. 7, vol. 270 suppl. 3, S88-S90, CrossRef.

Hunt, G.R. \& Gray, R.D. (2003b). Diversification and cumulative evolution in New Caledonian crow tool manufacture, in "Proceedings of the Royal Society of London, Series B", Apr. 22, vol. 270, no. 1515, p. 867-874, CrossRef.

Hurford J.R., Studdert-Kennedy, M. \& Knight, C. (ed.) (1998). Approaches to the evolution of language: Social and cognitive bases, Cambridge.

Hyatt, C. W. (1998). Responses of gibbons (Hylobates lar) to their mirror images, in “American Journal of Primatology”, vol. 45, no. 3, p. 307-311, CrossRef.

Interdisciplinaritatea $={ }^{* * *}$, Interdisciplinaritatea și științele umane [Interdisciplinarity and the Humanities], București, 1986. van Inwagen, P. (1983). An essay on Free Will, New York.

Irons, W. (1998). Adaptively relevant environments versus the environment of evolutionary adaptedness, in "Evolutionary Anthropology", vol. 6, no., 6, p. 194-204, CrossRef.

James, W. (1879). Are we automata?, in "Mind", vol. 4, no. 13, p. 1-22, CrossRef.

Joyce, R., Calcott B., Sterelny K. \& Fraser B. (2013). Cooperation and it's Evolution, MIT.

Jozefowiez, J., Staddon, J.E.R. \& Cerutti, D.T. (2009). Metacognition in animals: how do we know that they know?, in "Comparative Cognition \& Behavior Reviews", 4, p. 29-39, CrossRef.

Jung, C. G. \& Pauli, W. (2012). The Interpretation of Nature and Psyche: Synchronicity - An Acausal Conecting Principle / The Influence of Archetypal Ideas on the Scientific Theories of Kepler, New York.

Kandel, E.R., Dudai, Y. \& Mayford, M.R. (2014). The Molecular and Systems Biology of Memory, in “Cell”, Mar. 27, vol. 157, no. 1, p. 163-186, CrossRef.

Kawamura, S. (1959). The process of sub-culture propagation among Japanese macaques, in "Primates", vol. 2, no. 1, p. 43-60, CrossRef.

Kaznatcheev, A. (2014). Misleading models: How learning can guide evolution, Feb. 7.

Keeley, B. (2004). Anthropomorphism, primatomorphism, mammalomorphism: understanding cross-species comparisons, in "Biology and Philosophy", Sept., vol. 19, no. 4, p. 521-540, CrossRef.

Keller, L. \& Gordon, E. (2009). The Lives of Ants, Oxford.

Keller, L. \& Surette, M.G. (2006). Communication in bacteria: an ecological and evolutionary perspective, in "Nature Reviews Microbiology", Apr., 4, p. 249-258, CrossRef.

Kellogg, W.N. \& Kellogg, L.A. (1933). The Ape and the Child: a study of Environmental Influence Upon Early Behavior, New York.

Kenward, B., Weir, A.A.S., Rutz, Ch. \& Kacelnik, A. (2005). Behavioural ecology: Tool manufacture by naive juvenile crows, in "Nature", Jan. 13, vol. 433, no. 7022, p. 121, CrossRef.

Klein, R.G. (2009). The human career: Human biological and cultural origins, Chicago.

Klein, R. G. \& Blake, E. (2002). The dawn of human culture, New York.

Koehler, W. (1976). The mentality of apes, London, Toronto.

Kohlstedt, S. G. \& Kaiser, D. (2003). Science and the American Century: Readings from "Isis", Chicago.

Kopps, A. M., Ackermann, C. Y., Sherwin, W. B., Allen, S.J., Bejder, L. \& Krützen M. (2014). Cultural transmission of tool use combined with habitat specializations leads to fine-scale genetic structure in bottlenose dolphins, in "Proceedings of the Royal Society B”, Mar. 19, vol. 281, no. 1782, CrossRef.

Krützen, M., Kreicker, S., MacLeod, C. D., Learmonth, J., Kopps, A. M., Walsham, P. \& Allen, S.J. (2014). Cultural transmission of tool use by Indo-Pacific bottlenose dolphins (Tursiops sp.) provides access to a novel foraging niche, in "Proceedings of the Royal Society B”, June, vol. 281, no. 1784, CrossRef.

Ladygina-Kohts, N.N. \& de Waal, F.B.M. (2002). Infant Chimpanzee and Human Child: A Classic 1935 Comparative Study of Ape Emotions and Intelligence, translator: B. Vekker, New York.

Lakatos, L. \& Janka, Z. (2008). Az emberi agy és intelligencia evolúciója, in "Ideggyógyászati Szemle”, July, vol. 61, no. 7-8, p. 220-229.

Laland, K.N. \& Brown, G. R. (2011). Sense and nonsense: Evolutionary perspectives on human behaviour, New York.

Laland, K.N. \& Galef, B. G. (2009). The Question of the Animal Culture, Harvard.

Lane, N. (2009). Life ascending: The ten great inventions of evolution, New York.

Leadbeater, E. (2015). What evolves in the evolution of social learning?, in "Journal of Zoology", Jan. 5, vol. 295, no. 1, p. 4-11, CrossRef.

Lefebvre, L. (2013). Brains, innovations, tools and cultural transmission in birds, non-human primates and fossils hominins, in "Frontiers in Human Neuroscience", June 6, vol. 7, no. 245, CrossRef.

Lefebvre, L., Nicolakakis, N. \& Boire, B. (2002). Tools and brains in birds, in "Behaviour”, vol. 139, p. 939-973, CrossRef.

Lenneberg, E.H. (1971). Of language, knowledge, apes, and brains, in "Journal of Psycholinguistic Research”, Mar., vol. 1, no. 1, p. 1-29, CrossRef.

Lenti-Boero, D. (2014). Early human communication helps in understanding language evolution, in "Behavioral and Brain 
Sciences", Dec., vol. 37, no. 6, p. 563-564, CrossRef.

Libet, B. (1985). Unconscious Cerebral Initiative and the Role of Conscious Will in Voluntary Action, in "Behavioral and Brain Sciences", 8, p. 529-566, CrossRef.

Lieberman, P. (2002). On the nature and evolution of the neural bases of human language, in "American Journal of Physical Anthropology. Supplement: Yearbook of Physical Anthropology", Dec., vol. 119, no. suppl. 35, p. 36-62, CrossRef.

Lindahl, B.I.B. (1997). Consciousness and biological evolution, in "Journal of Theoretical Biology", Aug. 21, vol. 187, no. 4, p. 613-629, CrossRef.

Linden, D.J. (2007). The accidental mind, Cambridge.

Lock, A. (ed.) (1978). Action, Gesture and Symbol, New York.

Lumsden, C. \& Wilson, E. (2005). Genes, Mind and Culture: The Coevolutionary Process, Singapore, New Jersey, London.

Lycett, S.J., Collard, M. \& McGrew, W.C. (2007). Phylogenetic analyses of behavior support existence of culture among wild chimpanzees, in "Proceedings of the National Academy of Sciences of the U.S.A.", vol. 104, no. 45, p. 17588-17592, CrossRef.

MacLarnon, A.M. \& Hewit, G.P. (1999). The evolution of human speech: The role of enhanced breathing control, in "American Journal of Physical Anthropology", July, vol. 109, no. 3, p. 341-363, CrossRef.

MacLean, E.L., Matthews, L.J., Hare, B.A., Nunn, C.L., Anderson, R.C., Aureli, F., Brannon, E.M., Call, J., Drea, C.M., Emery, N.J., Haun, D.B., Herrmann, E., Jacobs, L.F., Platt, M.L., Rosati, A.G., Sandel, A.A., Schroepfer, K.K., Seed, A. M., Tan, J., van Schaik, C.P. \& Wobber, V. (2012). How does cognition evolve? Phylogenetic comparative psychology, in "Animal cognition", Mar., vol. 15, no. 2, p. 223-238, CrossRef.

Majid, A., Bowerman, M., Kita, S., Haun, D. B. M. \& Levinson, St. C. (2004). Can language restructure cognition? The case for space, in "Trends in Cognitive Sciences", Mar., vol. 8, no. 3, p. 108-114, CrossRef.

Matsuzawa, T. (ed.) (2008). Primate origins of human cognition and behavior, Tokyo, Berlin, Heidelberg, New York.

Mattei, T.A. (2014). Speech as a breakthrough signaling resource in the cognitive evolution of biological complex adaptive systems, in "Behavioral and Brain Sciences", Dec., vol. 37, no. 6, p. 564-565, CrossRef.

Matthew, Fr. (2012). Quantum entanglement shows that reality can't be local, in "Nature Physics", Oct. 30, CrossRef.

Maynard Smith, J. \& Harper, D. (2003). Animal Signals, Oxford.

Maynard Smith, J. \& Szathmáry, E. (1995). The major transitions in evolution, Oxford.

McGrew, W. (1992). Chimpanzee Material Culture: Implications for Human Evolution, Cambridge, CrossRef.

McGrew, W. (2004). The Cultured Chimpanzee: Reflections on Cultural Primatology, Cambridge, CrossRef.

Mead, M. (1970). Culture and Commitment: A Study of the Generation Gap, New York.

Mead, M. (2012). Continuities in cultural evolution, New Brunswick.

Mead, M. (ed.) (2003). Cooperation and competition among primitive peoples, New Brunswick.

Megill, J. (2007). Naturalism, Physicalism and Epiphenomenalism, in "Philosophical Psychology", vol. 20, no.6, p. 681-686, CrossRef.

Meguerditchian, A., Taglialatela, J.P., Leavens, D. A. \& Hopkins, W.D. (2014). Why vocal production of atypical sounds in apes and its cerebral correlates have a lot to say about the origin of language, in "Behavioral and Brain Sciences", Dec., vol. 37, no. 6, p. 565-566, CrossRef.

Mellars, P. \& Stringer, Ch. B. (ed.) (1989). The human revolution: Behavioural and biologicalperspectives on the origins of modern humans, Princeton.

Merker, B. (2007). Consciousness without a cerebral cortex: A challenge for neuroscience and medicine, in "Behavioral and Brain Sciences", vol. 30, no. 1, p. 63-134, CrossRef.

Mesoudi, A. (2011). Cultural Evolution: How Darwinian Theory Can Explain Human Culture \& Synthesize the Social Sciences, Chicago, CrossRef.

Metcalfe, J. \& Shimamura, A.P. (1994). Metacognition: knowing about knowing, Cambridge.

Michod, R.E. (1996). Cooperation and conflict in the evolution of individuality. II. Conflict mediation, in "Proceedings of the Royal Society B: Biological Sciences", July 22, vol. 263, no. 1372, p. 813-822, CrossRef.

Michod, R.E. (1997). Cooperation and conflict in the evolution of individuality. I. Multilevel selection of the organism, in "The American Naturalist", Apr., vol. 149, no. 4, p. 607-645, CrossRef.

Michod, R.E. \& Roze, D. (2001). Cooperation and conflict in the evolution of multicellularity, in "Heredity" (Edinb), Jan., vol. 86, no. 1, p. 1-7, CrossRef.

Miller, E. K., Freedman, D.J. \& Wallis, J.D. (2002). The Prefrontal Cortex: Categories, Concepts and Cognition, in "Philosophical Transactions of the Royal Society B: Biological Sciences", Aug. 29, vol. 357, no. 1424 p. 1123-1136, CrossRef.

Moll, H. \& Tomasello, M. (2007). Cooperation and human cognition: the Vygotskian intelligence hypothesis, in "Philosophical Transactions of the Royal Society B: Biological Sciences", vol. 362, no. 1480, p. 639-648, CrossRef.

Morris, D. (1999). The naked ape: The controversial classic of man's origins, New York.

Moss, C. (1988). Elephant memories: Thirteen years in the life of an elephant family, New York.

Nadell, C.D., Bucci, V., Drescher, K., Levin, S.A., Bassler, B.L. \& Xavier, J. B. (2013). Cutting through the complexity of cell collectives, in "Proceedings of the Royal Society B: Biological Sciences", Jan 30, vol. 280, no. 1755, CrossRef.

Nelson, T.O. (ed.) (1992). Metacognition: Core readings, Toronto, CrossRef. 
Nesse, M.H. (ed.) (1995). Bio-aesthetics: bridging the gap between evolutionary theory and the arts.

Nisbett, R.E. \& Wilson, T.D. (1977). Telling More Than We Can Know: Verbal Reports on Mental Processes, in "Psychological Review”, vol. 84, no. 3, p. 231-259, CrossRef.

Nishida, T. (1968). The social group of wild chimpanzees in the Mahali Mountains, in "Primates", Sept., vol. 9, no. 3, p. 167-224, CrossRef.

Noad, M.J., Cato, D. H., Bryden, M. M., Jenner, M.-N. \& Jenner, K. C. S. (2000). Cultural revolution in whale songs, in "Nature”, Nov. 30, vol. 408, p. 537, CrossRef.

O’Bleness, M., Searles, V.B., Varki, A., Gagneux, P. \& Sikela, J.M. (2012). Evolution of genetic and genomic features unique to the human lineage, in "Nature Reviews Genetics”, Dec., vol. 13, no. 12, p. 853-866, CrossRef.

Oller, D.K. (2014). Phonation takes precedence over articulation in development as well as evolution of language, in "Behavioral and Brain Sciences", Dec., vol. 37, no. 6, p. 567-568, CrossRef.

Orban, G. A. \& Caruana, F. (2014). The neural basis of human tool use, in “Frontiers in psychology", Apr. 9, vol. 9, no. 5, p. 310, CrossRef.

Osborn, H.F. (1897). The limits of organic selection, in “The American Naturalist”, Nov., 31, p. 944-951, CrossRef.

Osborn, H.F. (2014). De la greci la Darwin [From the Greeks to Darwin], translated by Al. Gafton and A. Chirilă, Iași.

Parker, S.T. \& Gibson, K.R. (ed.) (1990). 'Language' and Intelligence in Monkeys and Apes: Comparative Developmental Perspectives, Cambridge, CrossRef.

Parsek, M.R. \& Greenberg, E.P. (2005). Sociomicrobiology: the connections between quorum sensing and biofilms, in "Trends Microbiology", Jan, 1, p. 27-33, CrossRef.

Passingham, R. (1982). The human primate, London.

Pasternak, C. (ed.) (2007). What makes us human?, Oxford.

Patterson, F. G. \& Linden, E. (1981). The education of Koko, New York.

Payne, K. \& Payne, R. (1985). Large-scale changes over 19 years in songs of humpback whales in Bermuda, in "Zeitschrift für Tierpsychologie”, vol. 68, no. 2, p. 89-114, CrossRef.

Penn, D.C., Holyoak, K.J. \& Povinelli, D.J. (2008). Darwin's mistake: explaining the discontinuity between human and nonhuman minds, in "Behavioral and Brain Sciences", Apr., 31, p. 109-130, CrossRef.

Perry, S. \& Manson, J. (2003). Traditions in monkeys, in "Evolutionary Anthropology”, Apr., vol. 12, no. 2, p. 71-81, CrossRef.

Pinker, St. (1984). Language Learnability and Language Development, Cambridge.

Pinker, St. (1997). How the mind works, New York.

Pinker, St. \& Bloom, P. (1990). Natural language and natural selection, in "Behavioral and Brain Sciences", vol. 13, no. 4, p. 707784, CrossRef.

Popper, K. (2002). The Logic of Scientific Discovery, London.

Popper, K. (2012). The Two Fundamental Problems of the Theory of Knowledge, London, New York.

Povinelli, D. (2003). Folk Physics for Apes: The Chimpanzee's theory of how the world works, Oxford, CrossRef.

Povinelli, D.J., Gallup, G.G.jr., Eddy, T.J., Bierschwale, D.T., Engstrom, M.C., Perilloux, H.C. \& Toxopeus, I.B. (1997). Chimpanzees recognize themselves in mirrors, in "Animal Behaviour”, May 2, vol., 53, no. 5, p. 1083-1088, CrossRef.

Povinelli, D.J., Nelson, K.E. \& Boysen, S. T. (1990). Inferences about guessing and knowing by chimpanzees (Pan troglodytes), in "Journal of Comparative Psychology", 104, p. 203-210, CrossRef.

Povinelli, D.J., Rulf, A.B., Landau, K.R. \& Bierschwale, D.T. (1993). Self-recognition in chimpanzees (Pan troglodytes): distribution, ontogeny, and patterns of emergence, in "Journal of Comparative Psychology", Dec., vol. 107, no. 4, p. 347372, CrossRef.

Power, M. (1991). The Egalitarians: Human and chimpanzee, Cambridge, CrossRef.

Premack, D. (1971). Language in Chimpanzee?, in "Science", vol. 172, no. 3985, p. 808-822, CrossRef.

Premack, D. (2007). Human and animal cognition: continuity and discontinuity, in "Proceedings of the National Academy of Sciences of the U.S.A.”, Aug. 28, vol. 104, no. 5, p. 13861-13867, CrossRef.

Premack, D. (2010). Why Humans Are Unique. Three Theories, in "Perspectives on Psychological Science”, Jan., vol. 5, no. 1, p. 22-31, CrossRef.

Premack, D. \& Premack, J. (1983). The mind of an ape, New York.

Premack, D. \& Woodruff, G. (1978). Does the chimpanzee have a theory of mind?, in "Behavioral and Brain Sciences", Dec., vol. 1, no. 4, p. 515-526. [Call, J. \& Tomasello, M. (2008). Does the chimpanzee have a theory of mind? 30 years later, in "Trends in Cognitive Sciences", May, vol. 12, no. 5, p. 187-192, CrossRef].

Preuss, T.M. (2012). Human brain evolution: From gene discovery to phenotype discovery, in "Proceedings of the National Academy of Sciences of the U.S.A.", June, 109, suppl. 1, p. 10709-10716, CrossRef.

Prigogine, I. \& Stengers, I. (1984). Noua alianță. Metomorfoza științtei, translated by C. Boico and Z. Manolescu, București, 1984.

Pross, A. (2012). What is life? How chemistry becomes biology, Oxford.

Pruetz, J. \& Bertolani, P. (2007). Savanna chimpanzees, Pan troglodytes verus, hunt with tools, in "Current Biology", Mar. 6, vol. 17, no. 6, p. 1-6 CrossRef.

Prusiner, S.B. (1998). Prions, in "Proceedings of the National Academy of Sciences of the U.S.A.", Nov. 10, no. 95, vol. 23, 
p. $13363-13383$.

Purpura, G.J. (2006). In Search of Human Uniqueness, in "Philosophical Psychology”, vol. 19, no. 4, p. 443-461, CrossRef.

Pușcariu, S. (1994). Limba română [The Romanian Language], II. Rostirea [Utterance], București (1 ${ }^{\text {st }}$ ed.: 1959).

Raby, C.R., Alexis, D.M., Dickinson, A. \& Clayton, N.S. (2007). Planning for the future by western scrub-jays, in "Nature", Febr. 22, vol. 445, no. 7130, p. 919-921, CrossRef.

Rainey, P.B. \& Rainey, K. (2003). Evolution of cooperation and conflict in experimental bacterial populations, in "Nature", Sept. 4, 425, p. 72-74, CrossRef.

Ramsey, G. (2013). Culture in Humans and other Animals, in "Biology and Philosophy", vol. 28, no. 3, p. 457-479, CrossRef.

Rădulescu-Motru, C. (1932). Vocația. Factor hotărîtor in cultura popoarelor [Vocation. A Decisive Factor in the Culture of Peoples], București.

Rădulescu-Motru, C. (1998). Psihologia poporului român [The Psychology of the Romanian Peoples], edited by Al. Boboc, București.

Reid, Ch. R., Garnier, S., Beekman, M. \& Latty, T. (2015). Information integration and multiattribute decision making in nonneuronal organisms, in "Animal Behaviour", Febr., 100, p. 44-50, CrossRef.

Reiss, D. \& Marino, L. (2001). Mirror self-recognition in the bottlenose dolphin: a case of cognitive convergence, in "Proceedings of National Acadademy of Scienced of the U.S.A.,, vol. 98, no. 10, p. 5937-5942, CrossRef.

Rendell, L. \& Whitehead, H. (2001). Culture in whales and dolphins, in "Behavioral and Brain Sciences", vol. 24 no. 2, p. 309382, CrossRef.

Rendell, L., Boyd, R., Cownden, D., Enquist, M., Eriksson, K., Feldman, M.W., Fogarty, L., Ghirlanda, S., Lillicrap, T. \& Laland, K. N. (2010). Why Copy Others? Insights from the Social Learning Strategies Tournament, in "Science", Apr. 9, vol. 328, no. 5975, p. 208-213, CrossRef.

Richerson, P.J. \& Boyd, R. (2005). Not By Genes Alone: How Culture Transformed Human Evolution, Chicago, CrossRef.

Rico-Gray, V. \& Oliveira, P.O. (2007). The Ecology and Evolution of Ant-Plant Interactions, Chicago.

van Riel, G. \& Destrée, P. (ed.) (2009). Ancient perspectives on Aristotle’s De anima, Leuven.

Romanes, G. (1884). Animal intelligence, New York.

Romanes, G. (1900). Mental evolution in animals, with a posthumous essay on instinct by Charles Darwin, New York.

Rothschild, Fr.S. (2000). Creation and Evolution: A Biosemiotic Approach, New Jersey.

Runciman, W., Maynard Smith, J. \& Dunbar, R.I.M. (ed.) (1996). Evolution of social behaviour patterns in primates and man, Oxford.

Russon, A.E., Bard, K. A. \& Parker, S. T. (ed.) (1996). Reaching into thought: The minds of the great apes, Cambridge.

Sapolsky, R. (2006). Social cultures among nonhuman primates, in "Current Anthropology", vol. 47, no. 4, p. 641-648, CrossRef.

Savage-Rumbaugh, E.S. \& Fields, W.M. (2000). Linguistic, cultural and cognitive capacities of bonobos (Pan paniscus), in "Culture and Psychology", vol. 6, no. 2, p. 131-153, CrossRef.

Savage-Rumbaugh, E.S., Fields, W.M. \& Taglialatela, J.P. (2000). Ape Consciousness-Human Consciousness: A Perspective Informed by Language and Culture, in "American Zoologist", vol. 40, no. 6, p. 910-921, CrossRef.

Savage-Rumbaugh, E.S., McDonald, K., Sevcik, R.A., Hopkins, W.D. \& Hopkins, E. R. (1986). Spontaneoussymbol acquisition and communicative use by pygmy chimpanzees (Pan paniscus), in "Journal of Experimental Psychology: General”, sept., vol. 115 , no. 2, p. 211-235.

Savage-Rumbaugh, E.S., Murphy, J., Sevcik, R.A., Brakke, K.E., Williams, S.L. \& Rumbaugh, D.M. (1993). Language comprehension in ape and child, in "Monographs of the Society for Research in Child Development", vol. 58, no. 3-4, p. 1222, CrossRef.

Savage-Rumbaugh, E.S., Rumbaugh, D. M. \& McDonald, K. (1985). Language learning in two species of apes, in "Neuroscience and Biobehavioral Reviews", vol. 9, p. 653-665, CrossRef.

van Schaik, C.P. \& Knott, Ch.D. (2001). Geographic variation in tool use on Neesia fruits in orangutans, in "American Journal of Physical Anthropology", Apr., vol. 114, no. 4, p. 331-342, CrossRef.

van Schaik, C.P., Ancrenaz, M., Brogen, G., Galdikas, B., Knott, Ch.D., Singleton, I., Suzuki, A., Utami, S.S. \& Merrill, M. (2003). Orangutan cultures and the evolution of material culture, in "Science", Jan. 3, vol. 299, no. 5603, p. 102-105, CrossRef.

van Schaik, C.P., van Deaner, R. O. \& Merrill, M.Y. (1999). The conditions for tool use in primates: implications for the evolution of material culture, in "Journal of Human Evolution", 36, p. 719-741, CrossRef.

Schluessel, V. (2015). Who would have thought that 'Jaws' also has brains? Cognitive functions in elasmobranches, in "Animal Cognition", Jan., vol. 18, no. 1, p. 19-37, CrossRef.

Schrier, A. M., Harlow, H. F. \& Stollnitz, F. (2013). Behavior of non-human primates, New York, London, CrossRef.

Schürch, R. \& Grüter, Ch. (2014). Dancing Bees Improve Colony Foraging Success as Long-Term Benefits Outweigh Short-Term Costs, CrossRef.

Searle, J. (2005). Consciousness, în: Honderich T., The Oxford companion to philosophy, Oxford.

Shubin, N. (2008). Your inner fish: A journey into the 3.5-billion-year history of the human body, New York, 2008.

Snow, C.P. (1993). The Two Cultures, Cambridge, CrossRef. 
Soltis, J., Boyd, R. \& Richerson, P.J. (1995). Can Group-functional Behaviors Evolve by Cultural Group Selection? An Empirical Test, in "Current Anthropolgy", June, vol. 36, no. 3, p. 473-494, CrossRef.

Stenholm, S. (2011). The Quest for Reality: Bohr and Wittgenstein: Two Complementary Views, Oxford.

Suddendorf, Th. \& Corballis, M.C. (2007). The evolution offoresight: What is mental time travel, and is it unique to humans?, in "Behavoral and Brain Sciences", June, vol. 30, no. 3, p. 299-351, CrossRef.

Suddendorf, Th. \& Whiten, A. (2001). Mental evolution and development: Evidence for secondary representation in children, great apes, and other animals, in "Psychological Bulletin", Sept., vol. 127, no. 5, p. 629-650, CrossRef.

Taylor, A.H. \& Gray, R.D. (2014). Is there a link between the crafting of tools and the evolution of cognition?, in "Cognitive Science", Sept. 23, vol., 5, no. 6, p. 693-703, CrossRef.

Taylor, A.H., Miller, R. \& Gray, R.D. (2012). New Caledonian crows reason about hidden causal agents, in "Proceedings of the National Academy of Sciences", vol. 109, no. 40, p. 16389-16391, CrossRef.

Tebbich, S., Taborsky, M., Fessl, B. \& Blomqvist, D. (2001). Do woodpecker finches acquire tool-use by social learning?, in "Proceedings Biological Sciences", Nov. 7, vol. 268, no. 1382, p. 2189-2193, CrossRef.

Tennie, C., Call, J. \& Tomasello, M. (2009). Racheting up the ratchet: on the evolution of cumulative culture, in "Philosophical Transactions of the Royal Society B: Biology", Aug., vol. 364, no. 1528, p. 2405-2415, CrossRef.

Terrace, H.S. (1979). Nim: A chimpanzee who learned Sign Language, New York.

Thagard, P. (2010). The brain and the meaning of life, Princeton, CrossRef.

Théoret, H. \& Pascual-Leone, A. (2002). Language Acquisition: Do as You Hear, in "Current Biology", Oct. 29, vol. 12, no. 21, p. R736-737, CrossRef.

Thompson, J.N. (1994). The Coevolutionary Process, Chicago, CrossRef.

Thompson, J. N. (1999). The Evolution of Species Interactions, in “Science”, June 25, vol. 284, no. 5423, p. 2116-2118, CrossRef.

Thompson, J.N. (2005). The Geographic Mosaic of Coevolution, Chicago.

Thompson, J.N. (2013). Relentless Evolution, Chicago, CrossRef.

Thompson, J.N., Nuismer, S.L. \& Gomulkiewicz, R. (2002). Coevolution and Maladaptation, in "Integrative \& Comparative Biology”, Apr., vol. 42, no. 2, p. 381-387, CrossRef.

Thompson Klein, J. (1990). Interdisciplinarity: History, Theory and Practice, Detroit.

Thompson Klein, J. (1996). Crossing Boundaries: Knowledge, Disciplinarities and Interdisciplinarities.

Thorndike, E.L. (1911). Animal intelligence. Experimental studies, MacMillan.

Tomasello, M. (1999). The cultural origins of Human Cognition, Cambridge.

Tomasello, M. (2003). Constructing A Language. A Usage-Based Approach, Cambridge, Harvard.

Tomasello, M. (2008). The Origins of Human Communication, Cambridge, MIT.

Tomasello, M. \& Call, J. (1997). Primate cognition, Oxford.

Tomasello, M., Carpenter, M., Call, J., Behne, T. \& Moll, H. (2005). Understanding and sharing intentions: The origins of cultural cognition, in "Behavioral and Brain Sciences", Oct., vol. 28, no. 5, p. 675-691, CrossRef.

Tomasello M., Kruger, A.C. \& Ratner, H.H. (1993). Cultural Learning, in "Behavioral and Brain Sciences”, vol. 16, no. 3, p. 495-552, CrossRef.

Vaihinger, K. (2001). Filozofia lui ca și cum [The philosophy of as if], translated by L. Cotrău, București.

Vargha-Khadem, F., Watkins, K.E., Price, C.J., Ashburner, J., Alcock, K.J., Connelly, A., Frackowiack, R.S., Friston, K.J., Pembrey, M.E., Mishkin, M., Gadian, D. G. \& Passingham, R.E. (1998). Neural basis of an inherited speech and language disorder, in "Proceedings of the National Academy of Sciences of the U.S.A.", Oct. 13, vol., 21, no. 95, p. 12695-12700, CrossRef.

Vauclair, J. (1996). Animal Cognition: an introduction to Modern Comparative Psychology, Harvard.

deVore, I. (ed.) (1965). Primate Behavior:Field studies of monkeys and apes, Cambridge.

de Waal, F. (2003). GOOD NATURED: The Origins of Right and Wrong in Humans and Other Animals, Harvard, Cambridge, London.

de Waal, F. (2006). Primates and Philosophers, Princeton.

de Waal, F. B. M., Smith Churchland, P., Pievani, T. \& Parmigiani, S. (2014). Evolved Morality: The Biology and Philosophy of Human Conscience, Leiden, Boston.

Wald, H. (1970). Homo significans, București.

Wald, H. (1983). Ideea vine vorbind [The Idea Comes as You Speak], București.

Walker, St. (1983). Animal thought, London.

Wallman, J. (1992). Aping Language, Cambridge, CrossRef.

Watanabe A., Grodzinski U. \& Clayton N.S. (2014). Western scrub-jays allocate longer observation time to more valuable information, in "Animal cognition", July, vol. 17, no. 4, p. 859-867, CrossRef.

Watson, K.S., Townsend, S. W., Schel, A.M., Wilke, C., Wallace, E. K., Cheng, L., West, V. \& Slocombe, K. E. (2015). Vocal Learning in Functionally Referential Food Grunts of Chimpanzees, in "Current Biology", Feb. 16, vol. 25, no. 4, p. 495-499, CrossRef.

Weber, B. H. \& Depew, D.J. (ed.) (2003). Evolution and Learning. The Baldwin Effect Reconsidered, MIT.

Weiss, D.J., Hotchkin, C.F. \& Parks, S.E. (2014). Modification of spectral features by nonhuman primates, in "Behavioral and 
Brain Sciences", Dec., vol. 37, no. 6, p. 574-576, CrossRef.

West, S. A., Diggle, S.P., Buckling, A., Gardner, A. \& Griffin A.S. (2007a). The Social Lives of Microbes, in "Annual Review of Ecology, Evolution, and Systematics", 38, p. 53-77, CrossRef.

West, S. A., Griffin, A.S., Gardner, A. \& Diggle, S.P. (2006). Social evolution theory for microorganisms, in "Nature Reviews. Microbiology", Aug., 8, p. 597-607, CrossRef.

West, S. A., Griffin, A.S. \& Gardner, A. (2007b). Social semantics: altruism, cooperation, mutualism, strong reciprocity and group selection, in "Journal of Evolutionary Biology", Mar., 2, p. 415-432, CrossRef.

Whiten, A., Goodall, J., McGrew, W.C., Nishida, T., Reynolds, V., Sugiyama, Y., Tutin, C.E. G., Wrangham, R. W. \& Boesch, C. (1999). Cultures in chimpanzees, in "Nature", June 17, vol. 399, p. 682-685, CrossRef.

Whiten, A., Horner, V., Litchfield, C. \& Marshall-Pescini, S. (2004). How do apes ape?, in "Animal Learning \& Behavior”, Feb., vol. 32, no. 1, p. 36-52, CrossRef.

Whiten, A., Horner, V. \& de Waal, F. (2005). Conformity to cultural norms of tool use in chimpanzees, in "Nature", Sept. 29, vol. 437, p. 737-740, CrossRef.

Whiten, A. \& van Schaik, C. P. (2007). The Evolution of Animal 'Cultures' and Social Intelligence, in "Philosophical Transactions of the Royal Society B", Apr. 29, vol. 362, no. 1480, p. 603-620, CrossRef.

Whiten, A., Hinde, R.A., Laland, K. N. \& Stringer, C.B. (2007a). Culture Evolves, in "Philosophical Transactions of the Royal Society B", Apr. 29, vol. 366, no. 1480, p. 938-948, CrossRef.

Whiten, A., Hinde, R. A., Stringer, Ch.B. \& Laland, K. N. (ed.) (2011). Culture Evolves, Oxford, CrossRef.

Whiten, A., Spiteri, A., Horner, V., Bonnie, K.E., Lambeth, S.P., Schapiro, S.J. \& de Waal, F.B. (2007b). Transmission of multiple traditions within and between chimpanzee groups, in "Current Biology", June 19, vol. 17, no. 12, p. 1038-1043, CrossRef.

Williams, C. G. (1966). Adaptation and Natural Selection, Princeton, CrossRef.

Williams, C. G. (ed.) (1971). Group Selection, Chicago.

Wilson, D. C. (2002). Darwin's cathedral: Evolution, religion, and the nature of society, Chicago.

Wilson, E. O. (1975). Sociobiology: The New Synthesis, Cambridge.

Wilson, E. O. (1992). The diversity of life, Cambridge, Harvard.

Wilson, E. O. (1998). Consilience: The unity of knowledge. New York.

Winston, M.L. (2014). Bee Time: Lessons from the Hive, Harvard.

Witzany, G. (ed.) (2014). Biocommunication of Animals, Dordrecht, Heidelberg, New York, London, CrossRef.

Wollesen, T., Loesel, R. \& Wanninger, A. (2009). Pygmy squids and giant brains: mapping the complex cephalopod CNS by phalloidin staining of vibratome sections and whole-mount preparations, in "Journal of Neuroscience Methods", 179, p. 6367, CrossRef.

Wooldridge, D.E. (1963). Machinery of the Brain, New York.

Worms, R. (1895). Organisme et société, Paris.

Wrangham, R., Wilson, M. \& Muller, M. (2006). Comparative rates of violence in chimpanzees and humans, in "Primates", Jan., vol. 47, no. 1, p. 14-26, CrossRef.

Wright, R. (1995). The Moral Animal: Why We Are the Way We Are: The New Science of Evolutionary Psychology, New York.

Wuster, A. \& Babu, M. (2007). Facilitate Cell-to-Cell Comunication, in Wiley Encyclopedia of Chemical Biology, CrossRef.

Zenon, A. \& Olivier, E. (2014). Contribution of the basal ganglia to spoken language: Is speech production like the other motor skills?, "Behavioral and Brain Sciences", Dec., vol. 37, no. 6, p. 576-576, CrossRef.

Zhang, J., Webb, D.M. \& Podlaha, O. (2002). Accelerated protein evolution and origins of human-specific features: Foxp2 as an example, in "Genetics", Dec., vol. 162, no. 4, p. 1825-1835.

Zuckerman, S. (1999). The Social Life Of Monkeys And Apes, London, CrossRef. 